\title{
Hepatocarcinoma-intestine-pancreas/pancreatitis-associated protein (HIP/PAP) confers protection against hepatic fibrosis through downregulation of transforming growth factor $\beta$ receptor II
}

\author{
Qian $\mathrm{Li}^{1} \cdot$ Hanchao $\mathrm{Li}^{1} \cdot$ Yifei $\mathrm{Lv}^{2} \cdot$ Qiannan Zhang ${ }^{3} \cdot$ Xueting Zhang $^{3} \cdot$ Shuang $\mathrm{Li}^{3} \cdot$ Xiaoyan Zheng ${ }^{1} \cdot$ Yanhua Wang $^{1} \cdot$ \\ Zhiming $\mathrm{Hao}^{1}$
}

Received: 16 April 2019 / Revised: 23 July 2019 / Accepted: 30 July 2019 / Published online: 22 October 2019

(c) United States \& Canadian Academy of Pathology 2019

\begin{abstract}
Hepatocarcinoma-intestine-pancreas/pancreatitis-associated protein (HIP/PAP) has antimicrobial, antioxidant, antiinflammatory, mitogenic, and antiapoptotic effects and thus exerts important functions in the maintenance of integrity and homeostasis of several organs, such as the gastrointestinal tract, pancreas, and liver. Although the potent hepatoprotective effect of HIP/PAP has been validated, its impact on liver fibrosis has not been reported. In this study, we evaluated the role of HIP/PAP on hepatic fibrosis and explored the possible underlying mechanisms. We found that the expression of HIP/PAP and its mouse counterpart, Reg3B, was markedly upregulated in fibrotic human or mouse livers. Intraperitoneal (i.p.) interleukin (IL)-10, IL-6, and TNF- $\alpha$ but not TGF- $\beta 1$ significantly induced hepatic overexpression of Reg3B in mice. In both $\mathrm{CCl}_{4}$ and BDL liver fibrosis models, adenovirus-mediated ectopic expression of HIP/PAP markedly alleviated liver injury, inflammation, collagen deposition, hepatic stellate cell activation, and the overexpression of profibrotic cytokines, including transforming growth factor $\beta 1$ (TGF- $\beta 1$ ), platelet-derived growth factor (PDGF)-A, B, connective tissue growth factor (CTGF), and plasminogen activator inhibitor-1 (PAI-1), in mice. In vitro experiments demonstrated that, in addition to suppressing hepatic stellate cell proliferation and accelerating hepatocyte proliferation, HIP/PAP mitigated TGF- $\beta 1$-induced hepatic stellate cell activation, hepatocyte epithelialmesenchymal transition (EMT) and upregulated expression of profibrotic cytokines in both hepatic stellate cells and hepatocytes. Moreover, HIP/PAP attenuated the overexpression of TGF- $\beta$ receptor II (TGF- $\beta$ RII) in fibrotic mouse livers and decreased the basal expression of TGF- $\beta$ RII in nonfibrotic mouse livers as well as in cultured hepatocytes and hepatic stellate cells, which is at least partly attributable to the TGF- $\beta 1$-antagonizing function of HIP/PAP. This study indicates that increased expression of hepatic HIP/PAP serves as a countermeasure against liver injury and fibrosis. Exogenous supplementation of HIP/PAP might be a promising therapeutic agent for hepatic fibrosis as well as liver injury.
\end{abstract}

Supplementary information The online version of this article (https:// doi.org/10.1038/s41374-019-0314-x) contains supplementary material, which is available to authorized users.

Zhiming Hao

haozhm66@126.com

1 Department of Rheumatology, The First Affiliated Hospital of Xi'an Jiaotong University, Xi' an 710061, China

2 Department of Gastroenterology, The Third Affiliated Hospital of Xi'an Jiaotong University, Xi' an 710061, China

3 Department of Gastroenterology, The First Affiliated Hospital of Xi'an Jiaotong University, Xi' an 710061, China

\section{Introduction}

Liver fibrosis is a compensatory repair response to damage and a common intermediate pathological process of chronic liver diseases. Liver fibrosis due to various causes shares a common pathological process. Liver cell damage leads to the expression and/or release of proinflammatory factors, which in turn stimulate inflammatory cell infiltration. Inflammatory cell infiltration results in further damage to the liver by attacking liver cells and initiating fibrogenesis. Deposition of extracellular matrix (ECM), including collagens, proteoglycans, fibronectin, and laminin, eventually causes damage to the hepatic structure and leads to portal hypertension and liver failure [1,2]. 
Hepatic fibrosis involves complex cellular and molecular mechanisms. Myofibroblasts are regarded as the principal source of ECM. Activated hepatic stellate cells (HSCs) serve as the main source of myofibroblasts. In addition, bone marrow-derived or circulating mesenchymal cells, hepatocytes, cholangiocytes, or even endothelial cells may transdifferentiate into myofibroblasts [3]. The accumulation of myofibroblasts, the production and degradation of ECM, and the regeneration of hepatocytes involve complex intracellular events that are regulated by various extracellular factors, including growth factors, cytokines, chemokines, coagulation factors, and ECM components [2]. Among them are lectins, such as galectin-1 and galectin-3, which promote liver fibrosis, while dectin protects against liver fibrosis [4-6].

Hepatocarcinoma-intestine-pancreas/pancreatitis-associated protein (HIP/PAP), a member of the regenerating gene (Reg) family of C-type lectins, consists of 175 amino acid residues, with $66 \%$ homology to PAPI in rats and 69\% homology to Reg3B in mice [7, 8]. Under physiological conditions, HIP/PAP is secreted by some specialized epithelial cell subsets in the digestive tract, pancreas, kidney, and uterus and some populations of endocrine cells, such as the Paneth cells located in the small intestine, appendix, and ascending colon $[9,10]$. HIP/PAP is a multifunctional molecule that has antimicrobial [11], antioxidant [12, 13], anti-inflammatory [14, 15], mitogenic [16, 17], and antiapoptotic [12, 14-18] effects and thus exerts important functions in the maintenance of the integrity and homeostasis of several organs, such as the gastrointestinal tract, pancreas, and liver. HIP/PAP is a potent hepatoprotective factor that can protect against hepatocyte damage, promote hepatocyte regeneration, and inhibit liver inflammation in animal models [12, 16, 17], and a clinical trial of HIP/PAP treatment of fulminant liver failure has been conducted [19]. Liver injury and inflammation are the precursor lesions of fibrosis and cirrhosis. Therefore, we propose that HIP/PAP might have an antifibrotic function in the liver.

In this study, we first determined the expression of HIP/ PAP (Reg3B) in human and mouse fibrotic livers and explored the factors regulating hepatic HIP/PAP (Reg3B) expression. Next, the effect of adenovirus-mediated ectopic $\mathrm{HIP} / \mathrm{PAP}$ expression on $\mathrm{CCl}_{4}$ - and bile duct ligation (BDL)induced murine hepatic fibrosis was observed. Moreover, the underlying mechanisms for the antifibrotic effect of HIP/PAP were explored by in vivo and in vitro experiments.

\section{Materials and methods}

\section{Human liver tissue specimens}

Ten normal liver tissue specimens were collected from the patients undergoing surgical resection for metastatic hepatic malignancies, and ten cirrhotic liver specimens were from the patients who underwent liver transplantation at the First Affiliated Hospital of Xi'an Jiaotong University. Informed consent was obtained from each patient after surgery, and the study was approved by the Institutional Review Board.

\section{Generation of recombinant adenoviruses}

Replication-incompetent adenovirus (sero-type 5) with deletions in E1/E3 $(\Delta \mathrm{E} 1 / \mathrm{E} 3)$ carrying the $\mathrm{C}$-terminus $6 \times$ his-tagged HIP/PAP (AdHIP/PAP) or green fluorescence protein (AdGFP) were constructed using the AdEa$\mathrm{sy}^{\mathrm{TM}}$ Adenovirus Vector System (Stratagene, La Jolla, CA, USA) as described previously [15]. The titers of the recombinant adenoviruses were determined by plaqueforming assays of HEK293 cells and are expressed as plaque-forming units (PFUs). Viral stocks were stored at $-80^{\circ} \mathrm{C}$ until use.

\section{Animals and experimental protocol}

Specific pathogen-free, inbred male ICR mice (6 weeks old) weighing $25-30 \mathrm{~g}$ were provided by the Experimental Animal Center, Medical College of Xi'an Jiaotong University. The mice were maintained at $25^{\circ} \mathrm{C}$ with a $12-\mathrm{h}$ light/dark cycle and allowed free access to a chow diet and water. Animal handling was carried out in accordance with the NIH guidelines for the care and use of laboratory animals.

\section{Verification of adenovirus-mediated ectopic expression and possible toxic effects}

Thirty-five mice were randomly allocated into three groups: normal control (NC, five mice), AdGFP (15 mice), and AdHIP/PAP (15 mice). At day 0, AdGFP or AdHIP/PAP was administered intraperitoneally (i.p.) at a dose of $5 \times 10^{9} \mathrm{PFU} /$ mouse for mice in the two Ad groups, and the $\mathrm{NC}$ group was given an equal volume of PBS instead. After 3 days (day 3), NC mice and five mice in each of the two Ad groups were killed. At day 21, another five mice in each of the Ad groups were killed. The remaining mice received a second injection of the adenoviruses and were killed 3 days later (day 24) under chloral hydrate anesthesia. The serum was collected for measurements of ALT, AST, MPO activity, and MDA concentration with commercially available kits (Nanjing Jiancheng Bioengineering Institute, Nanjing, China). Paraffin sections were prepared for histological examination. Parts of the liver tissue were snap-frozen in liquid nitrogen to determine tissue MPO activity and extract DNA, RNA, and protein. 


\section{Verification of the factors inducing hepatic Reg3B expression}

To identify the factors inducing hepatic Reg3B expression, ICR mice (6 weeks old, weighing $25-30 \mathrm{~g}$, three mice in each group) were i.p. dosed with interleukin (IL)-10 (1 $\mu \mathrm{g})$, IL-6 $(0.5 \mu \mathrm{g})$, TNF- $\alpha(0.1 \mu \mathrm{g})$, and transforming growth factor $\beta 1$ (TGF- $\beta 1)(1 \mu \mathrm{g})$ or an equal volume $(0.5 \mathrm{ml})$ of normal saline and killed $24 \mathrm{~h}$ later. The liver, intestines, and pancreas were harvested for further experiments.

\section{Hepatic fibrosis modeling}

In the $\mathrm{CCl}_{4}$-induced hepatic fibrosis experiment, forty male ICR mice were randomly divided into four groups: $\mathrm{NC}, \mathrm{CCl}_{4}, \mathrm{AdGFP}+\mathrm{CCl}_{4}$, and AdHIP/PAP $+\mathrm{CCl}_{4}$. The mice in the three $\mathrm{CCl}_{4}$ groups were i.p. administered $\mathrm{CCl}_{4}$ $(1 \mathrm{ml} / \mathrm{kg}$ ) twice a week for 6 weeks to induce hepatic fibrosis. The mice in the $\mathrm{NC}$ group were given an equal volume of olive oil as the control. Three days before modeling and twenty-one days after the initiation of $\mathrm{CCl}_{4}$ injection, the mice in the two Ad groups received two i.p. injections of recombinant adenoviruses at a dose of $5 \times$ $10^{9} \mathrm{PFU} /$ mouse. The mice in the other two groups were given an equal volume of PBS instead. Twenty-four hours after the last $\mathrm{CCl}_{4}$ injection, the mice were euthanized under chloral hydrate anesthesia.

In the BDL model, twenty-eight ICR mice were divided into four groups: sham operation, BDL, AdGFP+BDL, and AdHIP/PAP+BDL. Three days prior to the operation, mice in the two Ad groups received i.p. adenoviruses as described above, while the mice in the other two groups were dosed with an equal volume of PBS. After $24 \mathrm{~h}$ of fasting, BDL was performed. Fourteen days after the operation, the mice were euthanized under chloral hydrate anesthesia.

\section{Measurements of serum aminotransferase activities and hepatic MDA content}

Serum ALT, AST, and hepatic MDA content were measured with commercially available kits (Nanjing Jiancheng Bioengineering Institute, Nanjing, China) following the manufacturer's instructions. Serum ALT and AST activities are expressed as Karmen unit/L. The liver tissue MDA content is expressed as $\mathrm{nmol} / \mathrm{mg}$ protein.

\section{Measurement of hepatic hydroxyproline content}

Hydroxyproline content in mouse liver tissue was determined using commercially available kits (Nanjing Jiancheng Bioengineering Institute, Nanjing, China) and expressed as $\mu \mathrm{g} / \mathrm{mg}$ wet liver tissue.

\section{Histology, immunohistochemistry (IHC) and cell immunofluorescence}

IHC was carried out using the Histostain ${ }^{\mathrm{TM}}$-Plus SP kit (Zhongshan Golden Bridge Biotechnology Co., Ltd, Beijing, China) following the manufacturer's instructions. The primary antibodies were mouse anti- $\alpha$-smooth muscle actin ( $\alpha$-SMA) mAb (1:800 dilution, Thermo, LabVision, Fremont, CA, USA), rabbit anti-Reg3B Ab (1:100, Lifespan Biosciences Inc., Seattle, WA, USA), and mouse antiReg3A mAb (1:100, R\&D Systems, Minneapolis, MN, USA). Human and mouse small intestines served as positive controls for HIP/PAP (Reg3B) IHC.

For immunofluorescence staining, the primary antibodies were mouse anti-vimentin mAb (1:100, Santa Cruz, CA, USA) and rabbit anti-E-cadherin pAb (1:50, Proteintech Group, Wuhan, China), followed by the secondary antibodies (FITC-labeled goat anti-mouse $\mathrm{IgG}$ and rhodamine (TRITC)-labeled goat anti-rabbit IgG, respectively, all from Zhongshan Jinqiao, Beijing, China, 1:100). Nuclei were labeled with DAPI (Thermo) for $10 \mathrm{~min}$, and images were captured with an Olympus microscope (Olympus Corporation, Tokyo, Japan).

\section{Terminal deoxynucleotidyl transferase-mediated dUTP-biotin nick end labeling assay (TUNEL)}

Apoptotic hepatocytes were labeled in situ using a TUNEL peroxidase detection kit (DeadEnd ${ }^{\mathrm{TM}}$ Colorimetric TUNEL System, Promega, Madison, WI) in accordance with the manufacturer's protocol. Apoptosis was quantified by counting the number of TUNEL-positive nuclei in at least ten random high-power fields (magnification, $\times 400$ ). The results are expressed as the apoptotic index (AI, a percentage of the labeled nuclei out of the total number of hepatocyte nuclei per high-power field).

\section{Cell culture and in vitro experiments}

LX-2 (human HSC), HSC-T6 (rat HSC), LO2 (human embryo liver cells), and RAW264.7 (mouse macrophages) cells are all from the Cell Bank of Type Culture Collection of Chinese Academy of Sciences (Shanghai, China) and cultured in Dulbecco's modified Eagle's medium (DMEM, HyClone GE Healthcare Life Sciences, South Logan, UT, USA) supplemented with $10 \%$ fetal bovine serum (FBS, HyClone) at $37^{\circ} \mathrm{C}$ under $5 \% \mathrm{CO}_{2}$. All experiments were performed in triplicate wells and repeated three times.

Cell proliferation was measured by using a CCK-8 assay (7Sea Pharmatech Co., Ltd, Shanghai, China). LX-2, HSCT6, and LO2 cells were inoculated into 96-well plates at 1000 cells per well. Then, the complete medium was replaced with DMEM supplemented with 2\% FBS and 
rHIP/PAP at various concentrations $(0,62.5,125$, and 250 $\mathrm{ng} / \mathrm{ml}$ ), and a CCK- 8 assay was performed once a day for 7 days to evaluate the cell number.

To test the antagonizing effect of rHIP/PAP on TGF- $\beta 1$-induced activation and transformation of HSCs and hepatocytes, cells were seeded into six-well plates at a density of $5 \times 10^{5}$ cells/well and treated with rHIP/PAP $(125 \mathrm{ng} / \mathrm{ml})$ and/or recombinant human TGF- $\beta 1$ (rhTGF$\beta 1$, Sino Biological, Inc., Beijing, China, $5 \mathrm{ng} / \mathrm{ml}$ ) for 24 $\mathrm{h}$. Then, the cells were harvested, and the total protein or RNA was extracted for further experiments.

\section{PCR and qRT-PCR}

Thirty-five cycle PCR for detecting the presence of the CMV-IE promoter sequence was performed with the primers $5^{\prime}$-TAGCTAGCGTTACATAACTTACGG-3' (forward) and 5'-CGGAATTCAAAACAAACTCCCAT TGAC-3' (reverse). Genomic DNA of the liver tissues served as the templates. The reaction products were electrophoresed on a $2 \%$ agarose gel.

Total RNA was extracted from cultured cells and liver tissues with TRIzol reagent (Thermo, Life Technologies, Carlsbad, CA) and quantified via a NanoDrop 2000 spectrophotometer (Thermo Fisher Scientific, Carlsbad, CA). Reverse transcription was performed with a Transcriptor First Strand cDNA Synthesis Kit (Roche Diagnostics Indianapolis, IN, USA). The relative abundance of each mRNA in the sample was determined using qRT-PCR with the corresponding primer pairs (Supplementary Table S1) and the FastStart Universal SYBR Green Master (ROX) (Roche Diagnostics Indianapolis, IN, USA) on an ABI StepOne Plus Real-time PCR Detection System (Applied Biosystems, Thermo Fisher Scientific, USA). Cycle threshold values were obtained from the StepOne ${ }^{\mathrm{TM}}$ Software Version 2.2.2 (Applied Biosystems). Data were analyzed using the 2- $\Delta \Delta C T$ method, and $\beta$-actin served as an internal control. The results are presented as the mean \pm standard deviation (SD) of triplicate reactions.

\section{Western blot analysis}

The frozen liver tissues and cultured cells were homogenized in RIPA lysis buffer containing protease inhibitors $(100 \mu \mathrm{g} / \mathrm{ml}$ PMSF, $1 \mu \mathrm{g} / \mathrm{ml}$ aprotinin). The primary antibodies included mouse anti- $6 \times$ his mAb (1:2000, SigmaAldrich Shanghai Trading, Co., Ltd, Shanghai, China), mouse anti-GFP mAb (Cell Signaling, Beverly, MA, USA), rabbit anti-Smad2/3 and anti-p-Smad2/3 Ab (Cell Signaling), anti- $\alpha$-SMA Ab, rabbit anti-Reg3B Ab, rabbit anti-vimentin pAb (1:1000), rabbit anti-E-cadherin pAb (1:500), mouse anti-TGF- $\beta$ RII mAb (1:100, Santa Cruz), and mouse anti- $\beta$-actin mAb (1:1,000 dilution, Santa
Cruz). The protein bands were visualized with enhanced chemiluminescence solution (ECL-Plus, GE Healthcare, Life Science, Uppsala, Sweden) and quantified using ImageJ (Broken Symmetry Software).

\section{Statistical analysis}

Statistical analyses were performed using GraphPad Prism software version 6 (GraphPad Software, Inc., La Jolla, CA, USA). The quantitative data are expressed as the mean \pm $\mathrm{SD}$. Differences between the two groups were examined using unpaired Student's $t$-test. Tukey's post hoc tests were performed after one-way analysis of variance in multiple comparisons among the groups. $P<0.05$ was considered to be statistically significant.

\section{Results}

\section{Expression of HIP/PAP (or Reg3B) is upregulated in fibrotic livers}

IHC showed that the expression of HIP/PAP was considerably elevated in cirrhotic human livers. In human normal liver tissues, weak positive staining was located in a few hepatocytes at the interface of portal tracts with parenchyma, as reported by Christa et al. [9, 10]. Human cirrhotic livers exhibited moderate or strong positive staining in hepatocytes, especially those in neighboring fibrous septa. In fibrous septa, hyperplastic bile ducts showed strong positive immunostaining, while other cells, most of which were myofibroblasts, exhibited negative immunostaining (Fig. 1a). qRT-PCR demonstrated that Reg3B mRNA expression was markedly increased at $12 \mathrm{~h}$, peaked at 2-3 days after $\mathrm{BDL}$ or $\mathrm{CCl}_{4}$ injection, and then declined slowly but remained at high levels until the end of the experiments (Fig. 1b, c). The increased hepatic expression of Reg3B was also validated by western blot and IHC analyses of murine fibrotic liver tissues after 6 weeks of $\mathrm{CCl}_{4}$ intoxication (Fig. 1d, e).

Next, we tested the possible mediators that induce the expression of hepatic Reg3B in mice during hepatic inflammation and fibrosis. HIPI expression was shown to be upregulated by IL-22 [20], IL-10 [21], and TNF- $\alpha$ [22] in rat acinar cells in vitro. Hence, we detected the expression of hepatic IL-22 and IL-10 in $\mathrm{CCl}_{4}$-treated and BDL mice. The results of qRT-PCR showed that hepatic IL-10 but not IL-22 mRNA levels were increased in the two models. Moreover, the increased hepatic IL-10 mRNA expression profile was grossly in agreement with that of Reg3B (Fig. 1f, g). Subsequently, we investigated the regulatory effects of IL-10, IL- 6 , TNF- $\alpha$, and TGF- $\beta 1$ on hepatic Reg3B expression. The results of qRT-PCR, western blots 
a
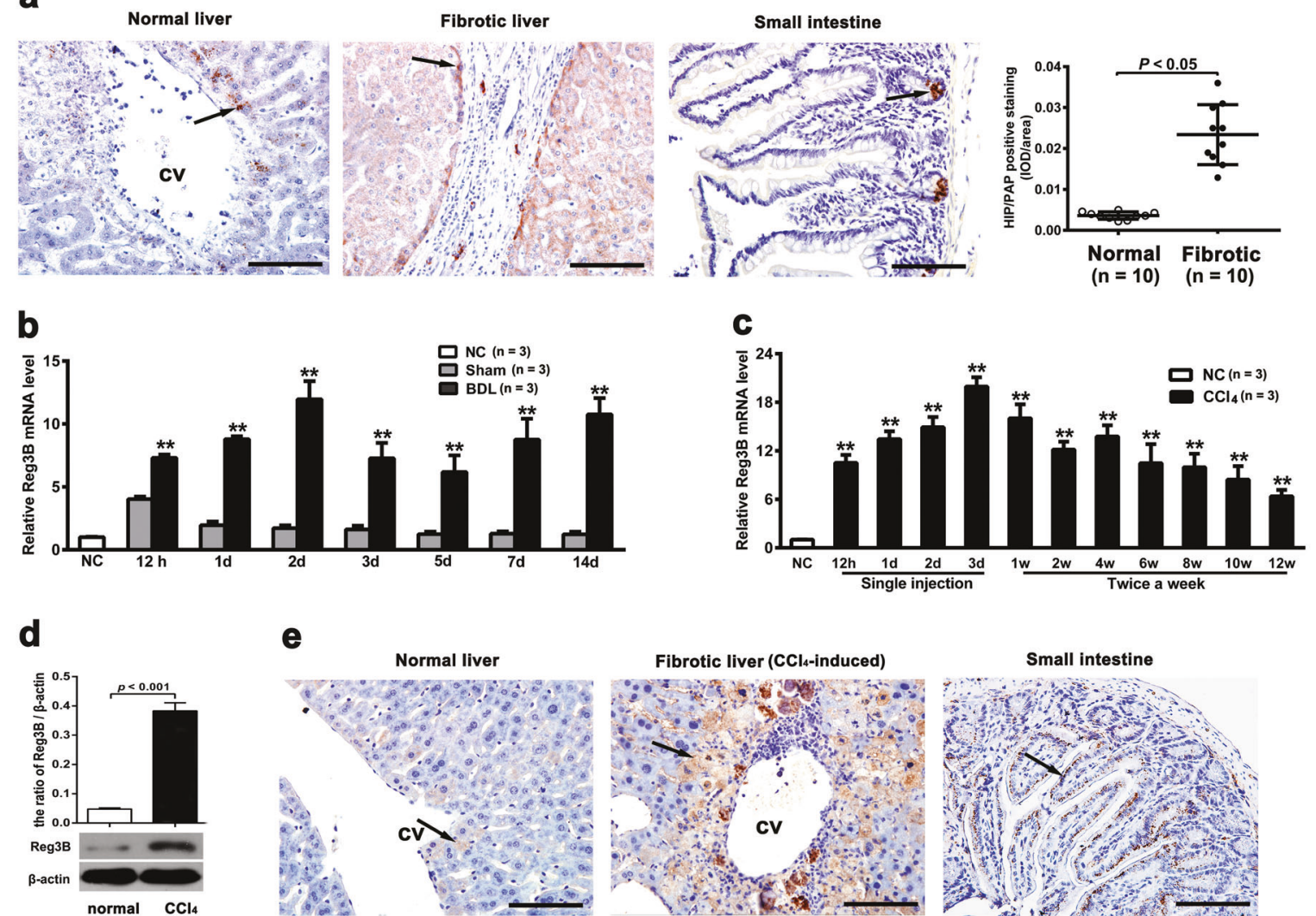

e

f
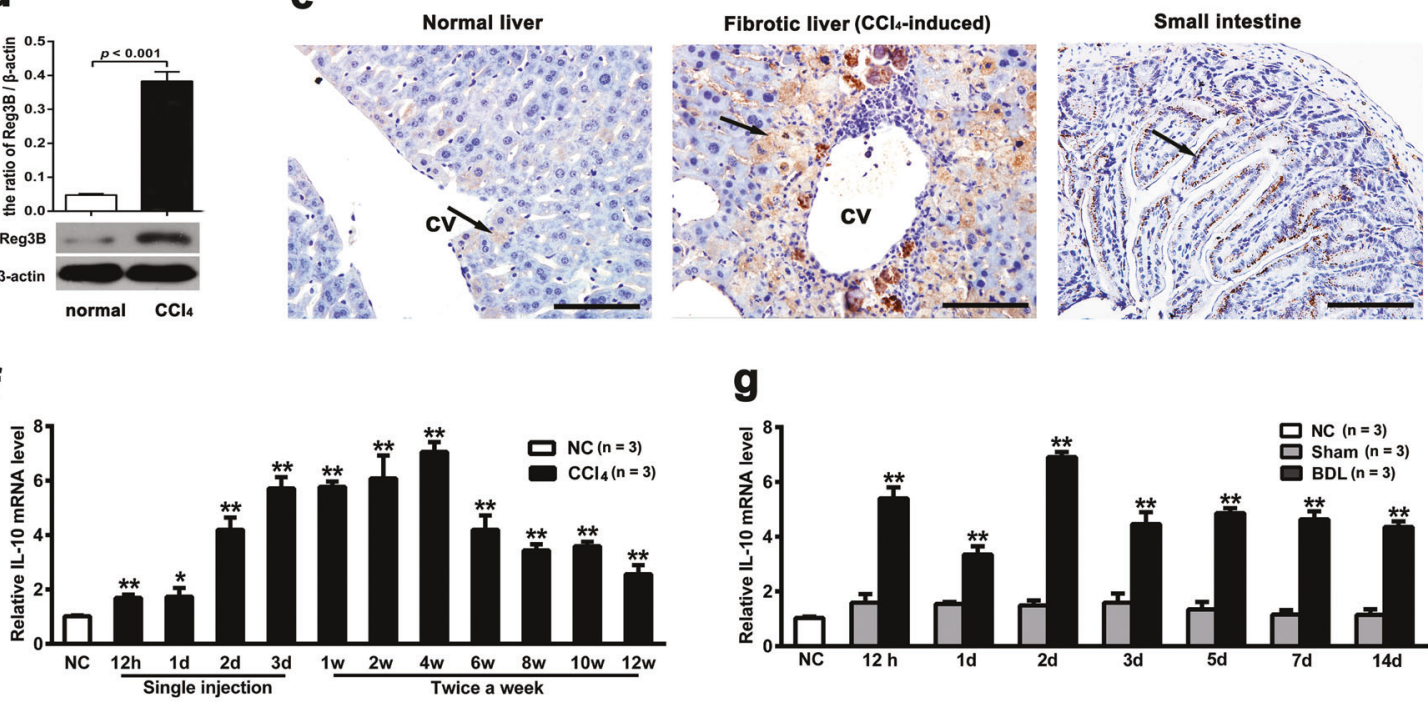

g

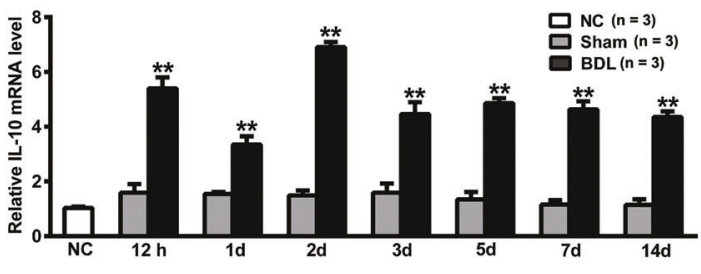

h

NS

TGF- $\beta 1$

TNF- $\alpha$
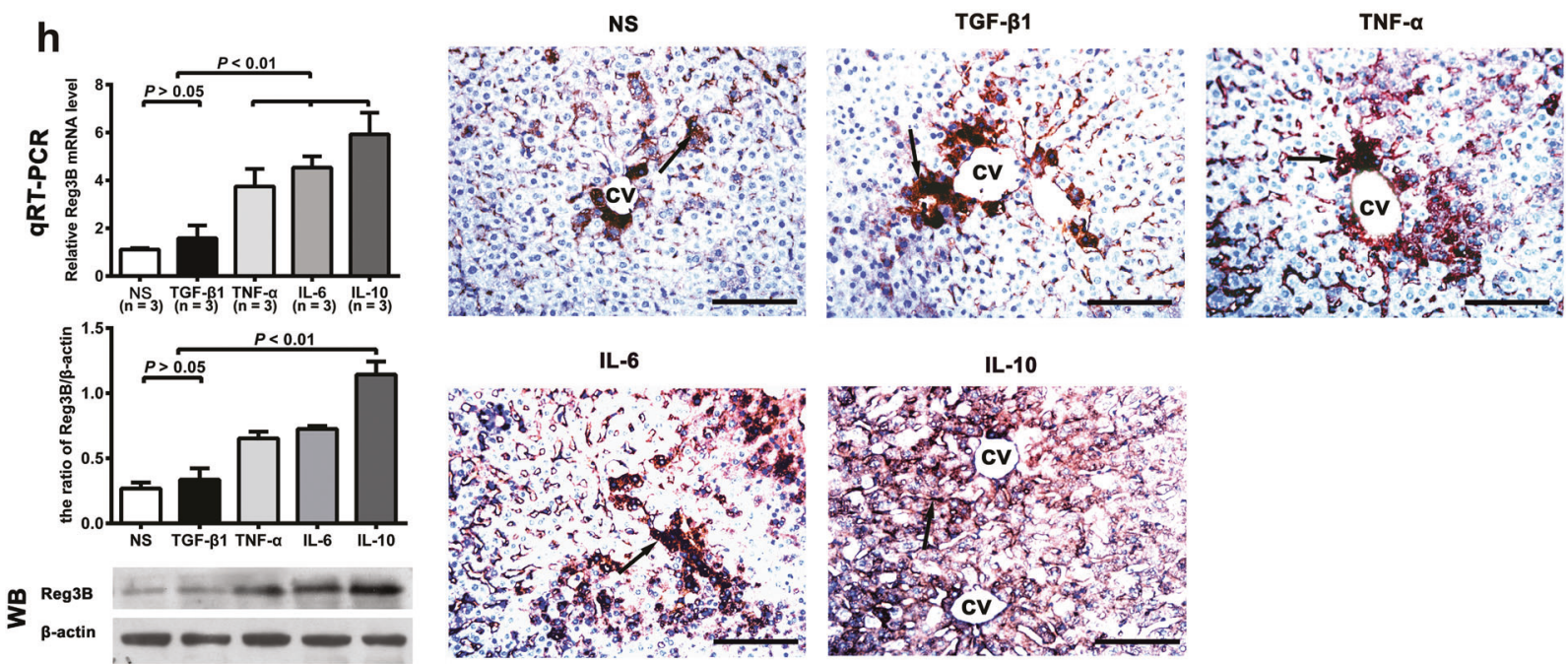
Fig. 1 The expression of HIP/PAP (Reg3B) is increased in human and mouse fibrotic livers. a Immunohistochemistry followed by image analysis showed that HIP/PAP expression is markedly higher in cirrhotic human liver than in normal human liver tissues. Human small intestine was used as a positive control. b Dynamic change in hepatic Reg3B mRNA expression in BDL mice. c qRT-PCR showed the overexpression and dynamic change of Reg3B mRNA in mouse liver tissues after $\mathrm{CCl}_{4}$ intoxication. Western blots (d) and $\mathrm{IHC}(\mathbf{e})$ verified the upregulated expression of Reg3B in mouse livers after 6 weeks of $\mathrm{CCl}_{4}$ treatment. The small intestine served as a positive control in IHC. Hepatic IL-10 mRNA expression was strongly increased in $\mathrm{CCl}_{4^{-}}$ treated (f) and BDL (g) mice. h Upregulation of hepatic Reg3B was induced by intraperitoneal IL-10, IL- 6 , and TNF- $\alpha$ but not TGF- $\beta 1$, as shown by qRT-PCR, western blots and IHC. Arrows indicate the positive immunostaining of HIP/PAP or Reg3B. CV central vein. Scale bars $=100 \mu \mathrm{m}$. Error bars indicate SD. $* P<0.05$, vs NC mice and $* * P<0.01$, vs NC mice or Sham mice at the same time points

and IHC revealed that i.p. IL-10, IL- 6 , and TNF- $\alpha$ led to marked upregulation of hepatic Reg3B expression (Fig. 1h). The inducing effects of IL-10, IL- 6 , and TNF- $\alpha$ on Reg3B expression were also observed in the pancreas and intestines. In addition, TGF- $\beta 1$ upregulated Reg3B expression in the pancreas and small intestine but not in the liver and large intestine (Supplementary Fig. 1).

\section{HIP/PAP alleviates $\mathrm{CCl}_{4}$ - and BDL-induced liver damage and subsequent inflammation}

Adenovirus possesses high immunogenicity and can elicit neutralizing antiadenovirus antibodies. Previous studies have verified that the repetitive intravenous application of adenoviruses in immune-competent adults was unsuccessful $[23,24]$. However, successful transduction by repetitive administration of adenoviruses can be achieved when they are intratracheally [25], intranasally [26], or intramuscularly [27] applied in mice and humans. In our study, to achieve high-level ectopic expression of HIP/PAP in mouse livers, the mice were repeatedly i.p. administered AdHIP/PAP. We first used PCR to detect the existence of the CMV-IE promoter sequence in the liver tissues to reflect the transduction of the adenoviruses. Then, western blot analysis was employed to determine adenovirus-mediated ectopic expression of GFP and HIP/PAP. As shown in Supplementary Figs. 2, 3 days after the first administration of AdGFP and AdHIP/PAP, obvious transduction of adenovirus vectors and ectopic expression of GFP and HIP/PAP, respectively, were observed. The transduction of adenovirus vectors and ectopic expression of foreign genes gradually subsided over time. Twenty-one days after the administration of adenoviruses, only weak transduction and ectopic expression were detected. The transduction and ectopic expression reappeared after the second administration of adenoviruses, although the expression levels were slightly lower compared with the first administration. Neither a single dose nor repeated i.p. $5 \times 10^{9} \mathrm{PFU} /$ mouse adenoviruses elevated the serum ALT, AST, serum, or hepatic tissue MPO activity or MDA content (data not shown) in the mice. In addition, histological examination of the H\&Estained liver sections showed that neither of the recombinant adenoviruses led to obvious pathological alterations (data not shown). Our results demonstrated that prolonged duration as well as high-level expression of foreign genes in the mouse liver mediated by repetitive i.p. adenovirus vectors was feasible.

Based on the above results, we exploited repeated administration of AdHIP/PAP to realize prolonged expression of HIP/PAP and observed its effects on $\mathrm{CCl}_{4}-$ and BDL-induced liver injury, inflammation and fibrosis. In line with previously reported results [12, 17], ectopic HIP/PAP displayed significant protective effects against liver injury. In the $\mathrm{CCl}_{4}$-intoxication model, administration of AdHIP/ PAP alleviated the elevation of serum ALT and AST activities (Fig. 2a, b), indicating a protective effect of HIP/ PAP on hepatocyte injury. Compared with the $\mathrm{CCl}_{4}$ and $\mathrm{AdGFP}+\mathrm{CCl}_{4}$ groups, AdHIP/PAP $+\mathrm{CCl}_{4}$ mice showed lower hepatic MDA content, suggesting that HIP/PAP ameliorated liver tissue oxidative injury in $\mathrm{CCl}_{4}$-treated mice (Fig. 2c). Apoptosis is a major death pattern of hepatocytes in response to various injurious factors, although hepatocytes may die through other pathways. The results of TUNEL staining showed that the hepatocyte apoptosis index in the AdHIP/PAP $+\mathrm{CCl}_{4}$ group was significantly lower than that in the other two $\mathrm{CCl}_{4}$ groups, demonstrating that HIP/PAP protects against $\mathrm{CCl}_{4}$-induced hepatocyte death (Fig. 2d, e). The protective effect of HIP/ PAP on liver injury was also validated in the BDL model, as demonstrated by decreased ALT (Fig. 2f), AST (Fig. 2g) activities, hepatic MDA content (Fig. 2h), and hepatocyte apoptosis (Fig. 2i, j) in AdHIP/PAP+BDL mice, which were lower than those in the other BDL groups.

IL-1 $\beta$, IL-6, TNF- $\alpha$, and IL-17A are representative proinflammatory cytokines, and IL-10 has an antiinflammatory effect; they all play essential roles in inflammation and subsequent fibrosis of the liver. To further investigate the possible anti-inflammatory effects of ectopic HIP/PAP on $\mathrm{CCl}_{4}$-induced liver injury in mice, we examined IL-1 $\beta$, IL-6, TNF- $\alpha$, IL-17A, and IL-10 mRNA levels in mouse livers by using qRT-PCR. As shown in Table 1, hepatic mRNA levels of IL-1 $\beta$, IL-6, TNF- $\alpha$, and IL-17A were upregulated by $\mathrm{CCl}_{4}$ intoxication and BDL, while ectopic expression of HIP/PAP significantly ameliorated these increases, except for IL-1 $\beta$, in the BDL model. In contrast, ectopic HIP/PAP further increased hepatic IL-10 expression, which was upregulated in both $\mathrm{CCl}_{4}$ and BDL models.

In support of the above results, another set of nonfibrotic animal experiments demonstrated that hepatic 

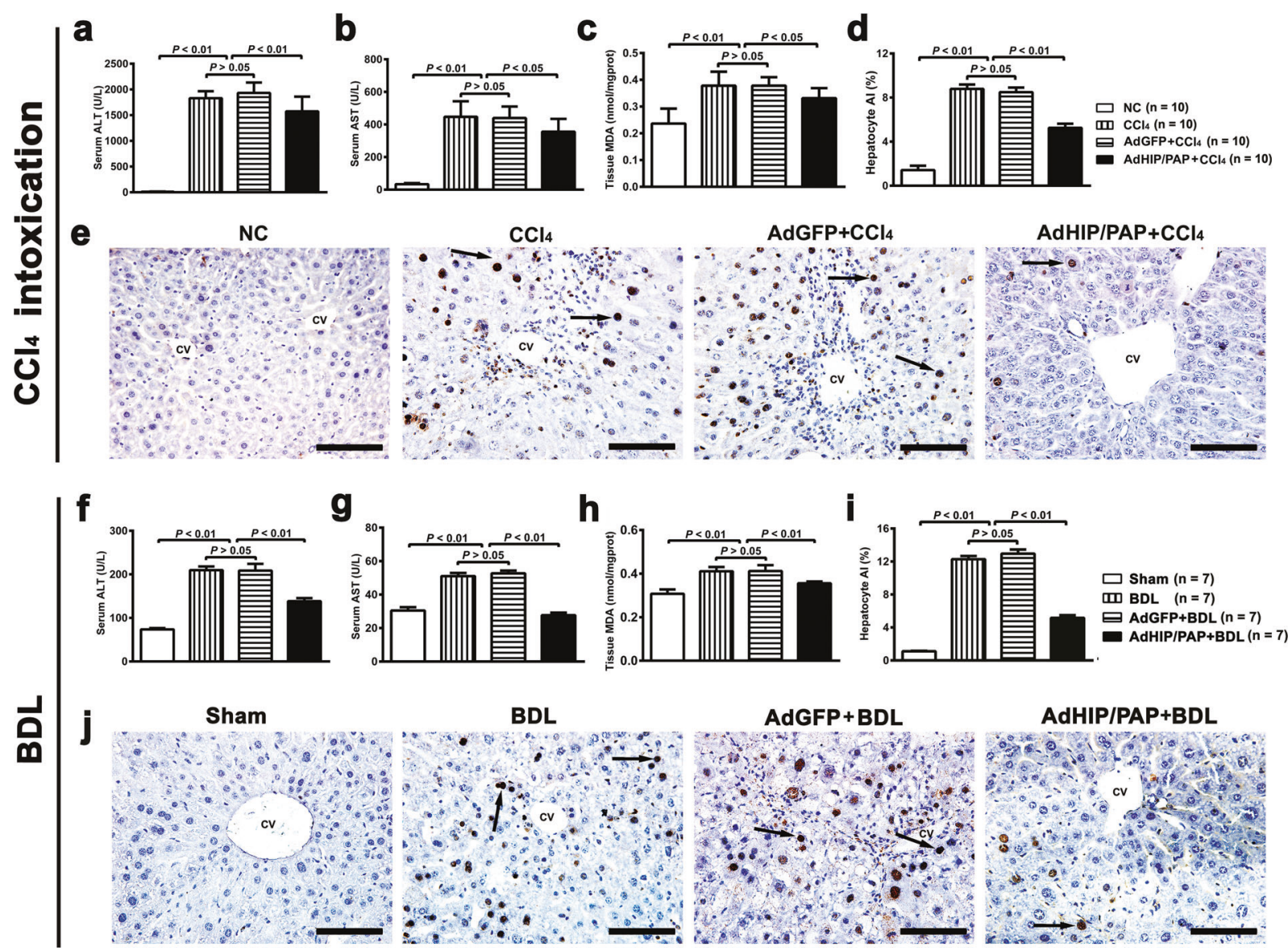

Fig. 2 Ectopic expression of HIP/PAP alleviates $\mathrm{CCl}_{4}-$ and BDLinduced liver injury and inflammation in mice. $\mathrm{CCl}_{4}$ intoxication resulted in liver injury as evidenced by markedly increased serum aminotransferase (ALT and AST) activities (a, b), hepatic MDA content (c), and hepatocyte apoptosis $(\mathbf{d}, \mathbf{e})$, while pretreatment with i. p. AdHIP/PAP significantly reduced all these increases. Similarly, AdHIP/PAP alleviated BDL-induced increases in serum ALT (f), AST (g), hepatic MDA content (h), and hepatocyte apoptosis (i, j). Error bars indicate SD. Arrows indicate positive TUNEL staining. CV central vein. Scale bars $=100 \mu \mathrm{m}$
IL-6, TNF- $\alpha$, and IL-17A expression was suppressed while IL-10 was increased by ectopic HIP/PAP (Table 2). We also tested the effects of rHIP/PAP on the expression of these cytokines in cultured LO2 and RAW264.7 cells, and the results showed that rHIP/PAP downregulated the proinflammatory cytokines, with the exception of IL-1 $\beta$ in RAW264.7 cells, and upregulated IL-10 expression (Table 3).

\section{HIP/PAP attenuates $\mathrm{CCl}_{4}$ - and $\mathrm{BDL}$-induced liver fibrosis in mice}

Next, we examined the effects of ectopic HIP/PAP expression on murine fibrosis. The results of picrosirius red staining and hydroxyproline content, which are specific indicators of collagen deposition [28], demonstrated that AdHIP/PAP significantly attenuated $\mathrm{CCl}_{4}$-induced liver fibrosis in mice (Fig. 3a, b). Furthermore, mice in the AdHIP/PAP $+\mathrm{CCl}_{4}$ group showed significantly downregulated Col1A2 (Fig. 3c) and Col3A1 (Fig. 3d) mRNA expression compared with the other two $\mathrm{CCl}_{4}$ groups, indicating that HIP/PAP reduced hepatic fibrogenesis in $\mathrm{CCl}_{4}$-intoxicated mice. Consistently, hepatic expression of ECM turnover markers, such as matrix metalloproteinase-13 (MMP-13) and tissue inhibitor of matrix metalloprotease-1 (TIMP-1), was significantly downregulated at the mRNA level in the AdHIP/PAP $+\mathrm{CCl}_{4}$ group compared to the other two $\mathrm{CCl}_{4}$ groups (Fig. 3e, f).

The protective effect of HIP/PAP on hepatic fibrosis was not exclusive to the $\mathrm{CCl}_{4}$-induced model. AdHIP/PAP also exhibited a significant protective effect against liver fibrosis in the BDL model, as indicated by the results of picrosirius red staining (Fig. 3g), hepatic hydroxyproline content determination (Fig. 3h), and CollA2 (Fig. 3i), Col3A1 (Fig. 3j), MMP-13 (Fig. 3k), and TIMP-1 mRNA evaluation (Fig. 31).

In contrast, in nonfibrotic mice, administration of AdHIP/PAP did not alter Col1A2 and Col3A1 mRNA expression in nonfibrotic mouse liver (data bot shown). 
Table 1 Effects of HIP/PAP on the expressions of hepatic inflammation-related cytokines and profibrotic factors in $\mathrm{CCl}_{4}$ -treated and BDL mice (fold change in mRNA expression)

\begin{tabular}{|c|c|c|c|c|}
\hline & $\mathrm{NC}(n=10)$ & $\mathrm{CCl} 4(n=10)$ & $\mathrm{AdGFP}+\mathrm{CCl} 4(n=10)$ & $\mathrm{AdHIP} / \mathrm{PAP}+\mathrm{CCl} 4(n=10)$ \\
\hline IL-1 $\beta$ & $1.06 \pm 0.35$ & $12.71 \pm 2.42 * *$ & $12.54 \pm 1.46^{* *}$ & $9.48 \pm 2.40^{\dagger \dagger}$ \\
\hline IL-6 & $1.03 \pm 0.42$ & $5.41 \pm 0.62 * *$ & $5.74 \pm 0.64 * *$ & $4.11 \pm 0.83^{\dagger \dagger}$ \\
\hline IL-17A & $1.00 \pm 0.06$ & $6.18 \pm 0.21 * *$ & $6.11 \pm 0.27 * *$ & $5.22 \pm 0.16^{\dagger \dagger}$ \\
\hline TNF- $\alpha$ & $1.00 \pm 0.18$ & $17.20 \pm 3.09 * *$ & $16.13 \pm 2.88 * *$ & $10.23 \pm 3.06^{\dagger \dagger}$ \\
\hline IL-10 & $1.01 \pm 0.03$ & $4.37 \pm 0.50 * *$ & $4.32 \pm 0.75^{* *}$ & $5.08 \pm 0.57^{\dagger}$ \\
\hline TGF- $\beta 1$ & $1.04 \pm 0.46$ & $2.10 \pm 0.62 * *$ & $2.06 \pm 0.61 * *$ & $1.39 \pm 0.34^{\dagger \dagger}$ \\
\hline PDGF-A & $1.07 \pm 0.23$ & $2.51 \pm 0.86^{* *}$ & $2.62 \pm 0.99 * *$ & $1.85 \pm 0.41^{\dagger}$ \\
\hline PDGF-B & $1.04 \pm 0.25$ & $2.33 \pm 0.60^{* *}$ & $2.37 \pm 0.61 * *$ & $1.63 \pm 0.38^{\dagger \dagger}$ \\
\hline CTGF & $1.06 \pm 0.37$ & $3.75 \pm 0.87 * *$ & $3.86 \pm 0.66^{* *}$ & $1.68 \pm 0.53^{\dagger \dagger}$ \\
\hline \multirow[t]{2}{*}{ PAI-1 } & $1.05 \pm 0.30$ & $50.42 \pm 9.76^{* *}$ & $49.18 \pm 3.19 * *$ & $39.87 \pm 9.98^{\dagger}$ \\
\hline & Sham $(n=7)$ & $\operatorname{BDL}(n=7)$ & $\mathrm{AdGFP}+\mathrm{BDL}(n=7)$ & AdHIP/PAP+BDL $(n=7)$ \\
\hline IL-1 $\beta$ & $0.99 \pm 0.06$ & $2.24 \pm 0.26^{* *}$ & $2.22 \pm 0.24 * *$ & $2.33 \pm 0.35$ \\
\hline IL-6 & $1.01 \pm 0.03$ & $4.44 \pm 0.87 * *$ & $4.28 \pm 0.38 * *$ & $3.19 \pm 0.44$ \\
\hline IL-17A & $1.02 \pm 0.07$ & $1.91 \pm 0.20^{* *}$ & $1.86 \pm 0.21 * *$ & $1.44 \pm 0.08^{\ddagger \ddagger}$ \\
\hline TNF- $\alpha$ & $1.02 \pm 0.06$ & $3.70 \pm 0.82 * *$ & $3.80 \pm 0.33 * *$ & $2.59 \pm 0.55^{\ddagger}$ \\
\hline IL-10 & $1.02 \pm 0.06$ & $2.33 \pm 0.19^{* *}$ & $2.39 \pm 0.33 * *$ & $3.32 \pm 0.63^{\ddagger \neq}$ \\
\hline TGF- $\beta 1$ & $1.01 \pm 0.05$ & $1.75 \pm 0.27 * *$ & $1.85 \pm 0.22 * *$ & $1.23 \pm 0.19^{\ddagger *}$ \\
\hline PDGF-A & $1.01 \pm 0.05$ & $2.85 \pm 0.41^{* *}$ & $2.85 \pm 0.30^{* *}$ & $2.06 \pm 0.29$ \\
\hline PDGF-B & $1.00 \pm 0.07$ & $1.25 \pm 0.47$ & $1.23 \pm 0.34$ & $1.13 \pm 0.36$ \\
\hline CTGF & $1.00 \pm 0.05$ & $4.29 \pm 0.23 * *$ & $4.34 \pm 0.37 * *$ & $3.64 \pm 0.43^{\ddagger}$ \\
\hline PAI-1 & $1.01 \pm 0.05$ & $38.05 \pm 2.41 * *$ & $38.11 \pm 5.04 * *$ & $31.01 \pm 2.36^{\ddagger}$ \\
\hline
\end{tabular}

Data from qRT-PCR were analyzed using the 2- $\Delta \Delta$ CT method, and $\beta$-actin served as an internal control. The results of fold change relative to $\mathrm{NC}$ or Sham group are presented as the mean $\pm \mathrm{SD}$

$* * P<0.01$, vs NC mice

${ }^{\dagger} P<0.05$ and ${ }^{\dagger \dagger} P<0.01$, vs $\mathrm{CCl} 4$ or $\mathrm{AdGFP}+\mathrm{CCl} 4$ group

${ }^{\ddagger} P<0.05$ and ${ }^{\sharp} P<0.01$, vs BDL or AdGFP+BDL group
Table 2 Impact of ectopic HIP/PAP on nonfibrotic mouse livers (fold change in mRNA expression)

\begin{tabular}{llll}
\hline & NC $(n=5)$ & AdGFP $(n=5)$ & AdHIP/PAP $(n=5)$ \\
\hline IL-1 $\beta$ & $1.05 \pm 0.07$ & $1.04 \pm 0.11$ & $1.11 \pm 0.12$ \\
IL-6 & $1.05 \pm 0.03$ & $1.00 \pm 0.08$ & $0.62 \pm 0.03^{* *}$ \\
IL-17A & $1.02 \pm 0.06$ & $1.01 \pm 0.08$ & $0.86 \pm 0.05^{*}$ \\
TNF- $\alpha$ & $1.03 \pm 0.10$ & $1.02 \pm 0.13$ & $0.68 \pm 0.07^{* *}$ \\
IL-10 & $1.01 \pm 0.02$ & $1.07 \pm 0.12$ & $2.50 \pm 0.21^{* *}$ \\
\hline
\end{tabular}

Data from qRT-PCR were analyzed using the $2-\Delta \Delta C T$ method and $\beta$-actin served as an internal control. The results of fold change relative to $\mathrm{NC}$ group are presented as the mean $\pm \mathrm{SD}$

$* P<0.05$ and $* * P<0.01$, vs NC or AdGFP

\section{HIP/PAP decreases profibrogenic factor production in both hepatocytes and hepatic stellate cells in fibrotic livers}

TGF- $\beta 1$, platelet-derived growth factor (PDGF)-A, B, connective tissue growth factor (CTGF), and plasminogen activator inhibitor-1 (PAI-1) are commonly regarded as the key profibrogenic cytokines in hepatic fibrosis. To explore
Table 3 HIP/PAP regulates the expression of inflammation-related cytokines in hepatocytes and macrophages (fold change in mRNA expression)

\begin{tabular}{llllll}
\hline & \multicolumn{2}{l}{ LO2 } & & \multicolumn{2}{l}{ RAW264.7 } \\
\cline { 2 - 3 } \cline { 5 - 6 } \cline { 5 - 6 } & Control & rHIP/PAP & & Control & rHIP/PAP \\
\hline IL-1 $\beta$ & $1.00 \pm 0.05$ & $0.62 \pm 0.03^{* *}$ & & $1.00 \pm 0.02$ & $1.10 \pm 0.09$ \\
IL-6 & $1.00 \pm 0.04$ & $0.89 \pm 0.04 *$ & & $1.00 \pm 0.02$ & $0.29 \pm 0.04 * *$ \\
IL-17A & $1.01 \pm 0.05$ & $0.60 \pm 0.08^{* *}$ & & $1.01 \pm 0.08$ & $0.81 \pm 0.06^{*}$ \\
TNF- $\alpha$ & $0.98 \pm 0.03$ & $0.59 \pm 0.03^{* *}$ & & $1.00 \pm 0.01$ & $0.41 \pm 0.02^{* *}$ \\
IL-10 & $1.01 \pm 0.04$ & $3.52 \pm 0.45^{* *}$ & & $0.98 \pm 0.04$ & $5.05 \pm 0.86^{* *}$ \\
\hline
\end{tabular}

Data from qRT-PCR were analyzed using the 2- $\Delta \Delta \mathrm{CT}$ method and $\beta$ actin served as an internal control. The results of fold change relative to control group are presented as the mean \pm SD of triplicate reactions from three separate experiments. Results are expressed as means \pm SD $* P<0.05$ and $* * P<0.01$, vs control in the same cells

the possible roles of HIP/PAP-mediated antifibrogenic effects in $\mathrm{CCl}_{4}-$ and BDL-induced hepatic fibrosis in mice, mRNAs of these cytokines were measured by qRT-PCR. The results showed that in $\mathrm{CCl}_{4}$ - and BDL-induced fibrotic mouse livers, the expression levels of TGF- $\beta 1$, PDGF-A, B, 

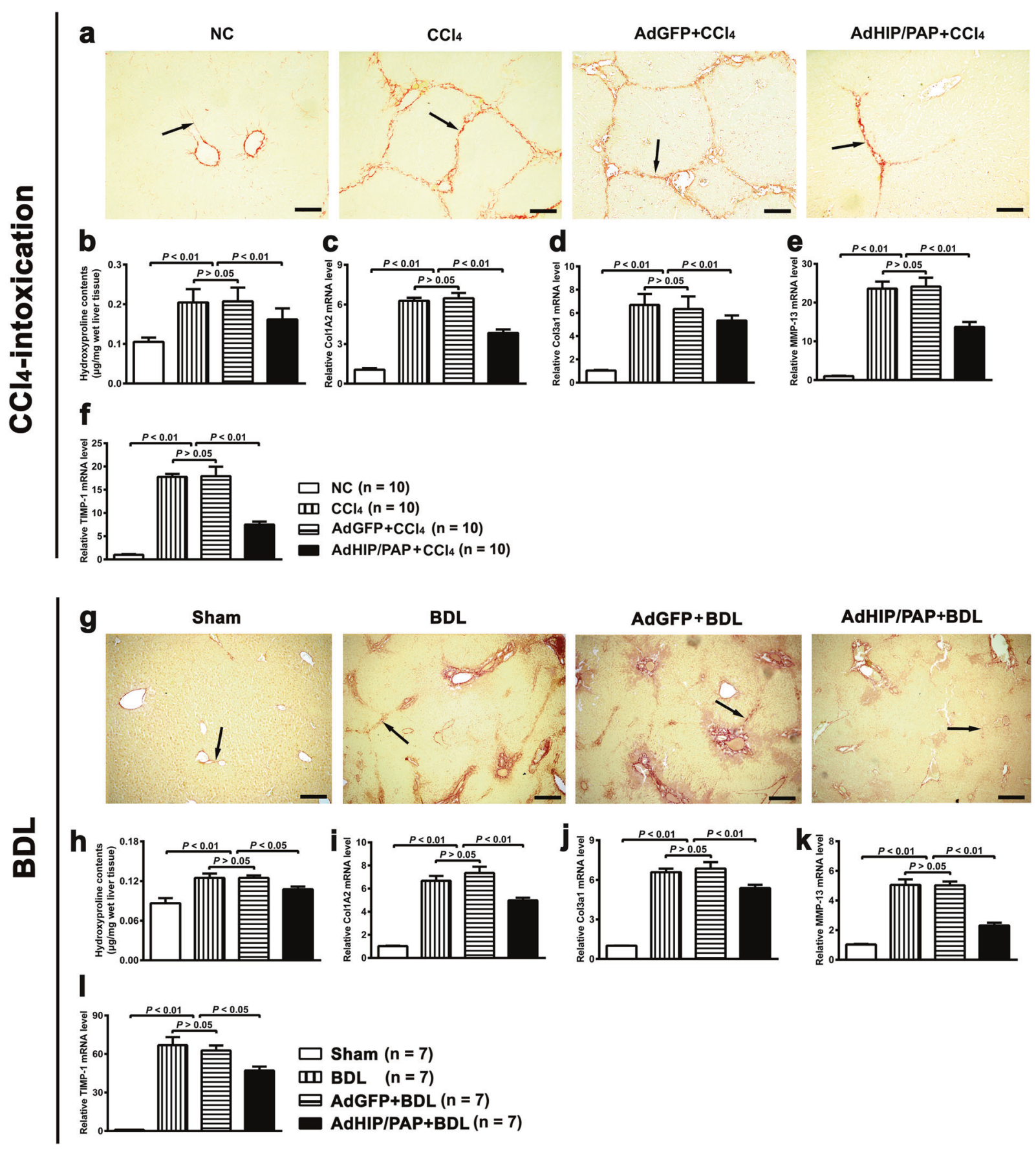

Fig. $3 \mathrm{HIP} / \mathrm{PAP}$ attenuates $\mathrm{CCl}_{4}-$ and BDL-induced hepatic fibrosis in mice. Picrosirius red staining of the liver tissues (a) and hepatic hydroxyproline content determination (b) showed that adenovirusmediated HIP/PAP ectopic expression significantly attenuated collagen deposition in $\mathrm{CCl}_{4}$-induced fibrotic mouse livers. Increased hepatic collagen synthesis and ECM turnover were significantly

CTGF, and PAI-1 were markedly increased at the mRNA level but significantly decreased by HIP/PAP (Table 1). In nonfibrotic mice, AdHIP/PAP increased hepatic PAI-1 mRNA levels but did not affect TGF- $\beta 1$, PDGF-A, B, or CTGF mRNA expression (data not shown). alleviated by $\mathrm{HIP} / \mathrm{PAP}$ in $\mathrm{CCl}_{4}$-treated mice, as indicated by qRT-PCR evaluation of hepatic Col1A2 (c), Col3A1 (d), MMP-13 (e), and TIMP-1 (f). The protective effect of AdHIP/PAP on liver fibrosis was also validated in a murine BDL model $(\mathbf{g}-\mathbf{l})$. Arrows indicate positive picrosirius staining. The results are presented as the mean $\pm \mathrm{SD}$. Scale bars $=100 \mu \mathrm{m}$

We further performed in vitro experiments with $\mathrm{LO}$, LX-2, HSC-T6, and RAW264.7 cells to clarify which cell type served as the target in regard to the decreased expression of the profibrotic factors. The results showed that the addition of rHIP/PAP significantly abated 
Table 4 HIP/PAP abates TGF- $\beta 1$-induced overexpression of profibrotic factors in hepatocytes and HSCs (fold change in mRNA expression)

\begin{tabular}{|c|c|c|c|c|}
\hline & Control & rHIP/PAP & TGF- $\beta 1$ & TGF $-\beta 1+$ rHIP/PAP \\
\hline \multicolumn{5}{|l|}{$\mathrm{LO} 2$} \\
\hline TGF- $\beta 1$ & $0.99 \pm 0.04$ & $0.94 \pm 0.05$ & $2.22 \pm 0.18^{\dagger \dagger}$ & $1.88 \pm 0.07^{\ddagger}$ \\
\hline CTGF & $1.03 \pm 0.06$ & $0.93 \pm 0.03$ & $2.44 \pm 0.29^{\dagger \dagger}$ & $1.94 \pm 0.09$ \\
\hline PDGF-A & $0.99 \pm 0.04$ & $0.93 \pm 0.04$ & $1.84 \pm 0.14^{\dagger \dagger}$ & $1.43 \pm 0.13^{\ddagger}$ \\
\hline PDGF-B & $1.01 \pm 0.01$ & $0.88 \pm 0.07$ & $2.07 \pm 0.14^{\dagger \dagger}$ & $1.68 \pm 0.09^{\ddagger}$ \\
\hline PAI-1 & $0.99 \pm 0.07$ & $1.09 \pm 0.12$ & $5.15 \pm 0.46^{\dagger \dagger}$ & $3.21 \pm 0.30^{\# \neq}$ \\
\hline \multicolumn{5}{|l|}{ LX-2 } \\
\hline TGF- $\beta 1$ & $0.99 \pm 0.07$ & $0.93 \pm 0.13$ & $1.81 \pm 0.05^{\dagger \dagger}$ & $1.31 \pm 0.16^{\text {护 }}$ \\
\hline CTGF & $0.99 \pm 0.04$ & $1.06 \pm 0.10$ & $9.68 \pm 0.12^{\dagger \dagger}$ & $9.08 \pm 0.21^{\text {\# }}$ \\
\hline PDGF-A & $1.01 \pm 0.04$ & $0.86 \pm 0.25$ & $2.95 \pm 0.24^{\dagger \dagger}$ & $2.15 \pm 0.13^{\ddagger \ddagger}$ \\
\hline PDGF-B & $1.02 \pm 0.03$ & $0.86 \pm 0.05$ & $2.50 \pm 0.50^{\dagger \dagger}$ & $1.55 \pm 0.01^{\text {क }}$ \\
\hline PAI-1 & $0.98 \pm 0.06$ & $0.98 \pm 0.11$ & $3.24 \pm 0.74^{\dagger \dagger}$ & $1.87 \pm 0.35^{\ddagger}$ \\
\hline \multicolumn{5}{|l|}{ HSC-T6 } \\
\hline TGF- $\beta 1$ & $0.99 \pm 0.06$ & $1.04 \pm 0.28$ & $2.48 \pm 0.16^{\dagger \dagger}$ & $1.58 \pm 0.13^{\ddagger}$ \\
\hline CTGF & $0.99 \pm 0.01$ & $0.78 \pm 0.23$ & $6.84 \pm 0.36^{\dagger \dagger}$ & 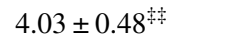 \\
\hline PDGF-A & $1.07 \pm 0.14$ & $1.07 \pm 0.22$ & $2.86 \pm 0.30^{\dagger \dagger}$ & $2.28 \pm 0.14^{\ddagger}$ \\
\hline PDGF-B & $1.03 \pm 0.08$ & $0.98 \pm 0.02$ & $3.65 \pm 0.30^{\dagger \dagger}$ & $2.00 \pm 0.22^{\ddagger}$ \\
\hline PAI-1 & $1.01 \pm 0.04$ & $0.87 \pm 0.23$ & $6.78 \pm 0.14^{\dagger \dagger}$ & $4.33 \pm 0.91^{\text {抹 }}$ \\
\hline
\end{tabular}

Data from qRT-PCR were analyzed using the 2- $\Delta \Delta$ CT method and $\beta$-actin served as an internal control. The results of fold change relative to control group are presented as the mean $\pm \mathrm{SD}$ of triplicate reactions from three separate experiments

${ }^{\dagger} P<0.01$, vs control and rHIP/PAP groups

${ }^{\ddagger} P<0.05,{ }^{\ddagger} P<0.01$, vs TGF- $\beta 1$ group

TGF- $\beta 1$-induced upregulation of TGF- $\beta 1$, PDGF-A, B, CTGF, and PAI-1 but did not affect their basal expression in LO2, LX-2, and HSC-T6 cells (Table 4) but not RAW264.7 cells (data not shown).

\section{HIP/PAP inhibits the activation of hepatic stellate cells in fibrotic livers}

To evaluate the effects of ectopic expression of HIP/PAP on the activation of HSCs in fibrotic mouse livers, the expression levels of $\alpha$-SMA and vimentin, which are wellknown markers of HSC activation [3], were assessed. As shown in Fig. 4, qRT-PCR and western blot analyses revealed that HIP/PAP attenuated the overexpression of $\alpha$ SMA (Fig. 4a, b) and vimentin (Fig. 4c, d) in $\mathrm{CCl}_{4}$-induced fibrotic mouse livers. The attenuating effect of HIP/PAP on $\mathrm{CCl}_{4}$-induced overexpression of hepatic $\alpha$-SMA was additionally confirmed by IHC (Fig. 4e). Similar effects of HIP/ PAP on the expression of $\alpha$-SMA and vimentin were also observed in BDL-induced fibrotic mouse livers (Fig. 4f-j). However, ectopic HIP/PAP expression in nonfibrotic mice failed to change hepatic $\alpha$-SMA and vimentin mRNA expression (data not shown).

To clarify whether HIP/PAP has a direct impact on HSC proliferation and activation, we performed an in vitro experiment with the immortal HSC lines LX-2 and HSC-
T6. The addition of rHIP/PAP suppressed the proliferation of LX-2 in a dose-dependent manner, with a peak at 125-250 ng/ml (Fig. 5a). Although rHIP/PAP showed a negligible effect on the basal expression of $\alpha$-SMA, vimentin, Col1A2, and Col3A1, it significantly mitigated TGF- $\beta 1$-induced overexpression of these molecules (Fig. 5b-g). The effect of HIP/PAP on HSC activation was further supported by the fact that rHIP/PAP attenuated Smad2/3 phosphorylation in TGF- $\beta 1$-stimulated LX-2 cells (Fig. 5h). Similar effects of rHIP/PAP on the proliferation and expression of $\alpha$-SMA, vimentin, Col1A2, and Col3A1 were also observed in HSC-T6 cells (Fig. 5i-m), clearly indicating that HIP/PAP exerts a direct inhibitory effect on the proliferation and TGF- $\beta 1$-induced activation of HSCs.

\section{HIP/PAP promotes proliferation while inhibiting the TGF- $\beta 1$-induced epithelial-mesenchymal transition (EMT) of hepatocytes}

The proliferation-promoting effect of HIP/PAP on hepatocytes has been reported elsewhere [16, 17]. In agreement with this finding, our in vitro experiment showed that $\mathrm{rHIP} / \mathrm{PAP}$ dose-dependently promoted the proliferation of LO2 cells with a peak at $125 \mathrm{ng} / \mathrm{ml}$ (Fig. 6a).

EMT of hepatocytes has been proposed to be a notable source of myofibroblasts, and TGF- $\beta 1$ potently promotes 

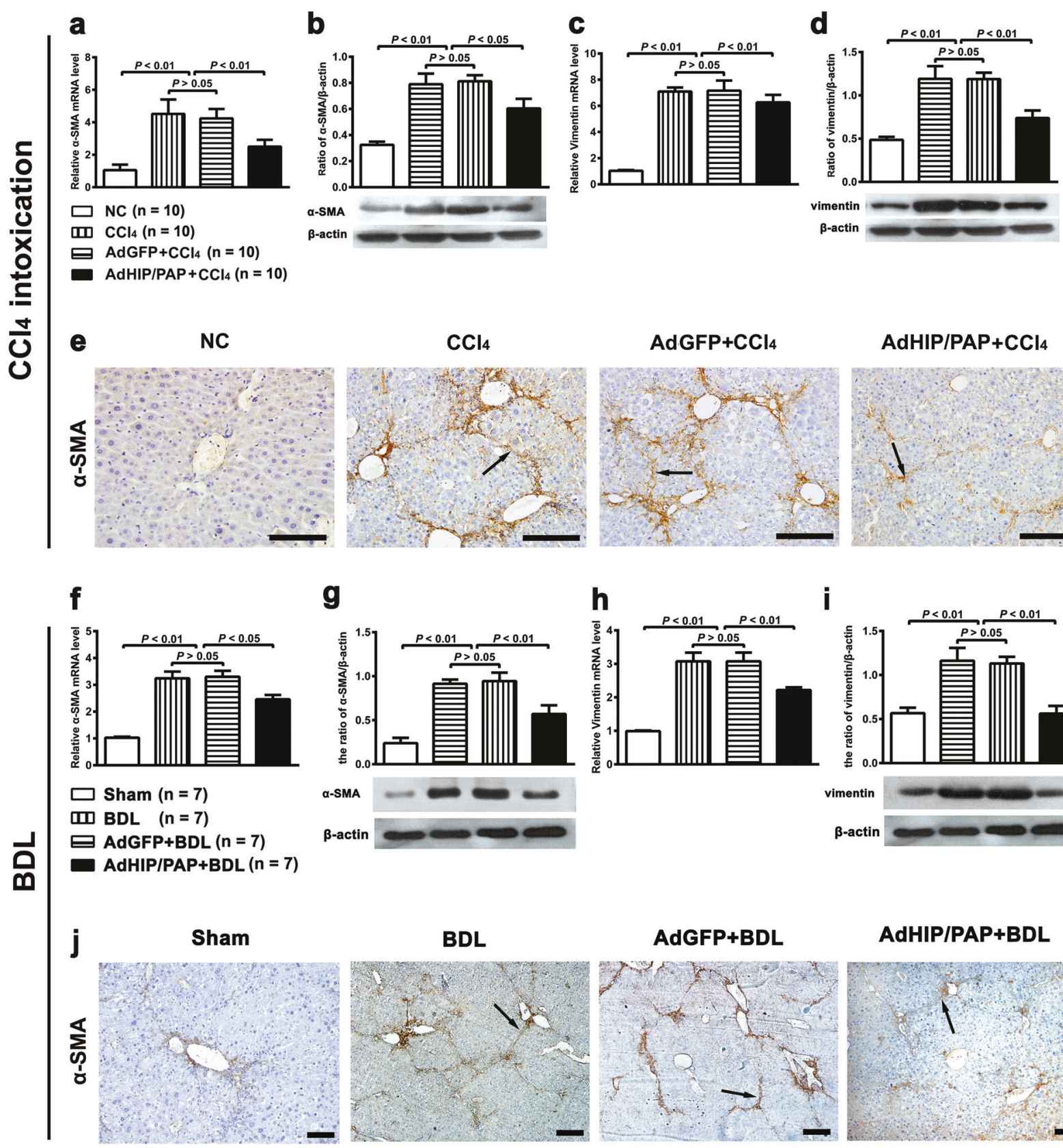

AdHIP/PAP+ $\mathrm{CCl}_{4}$
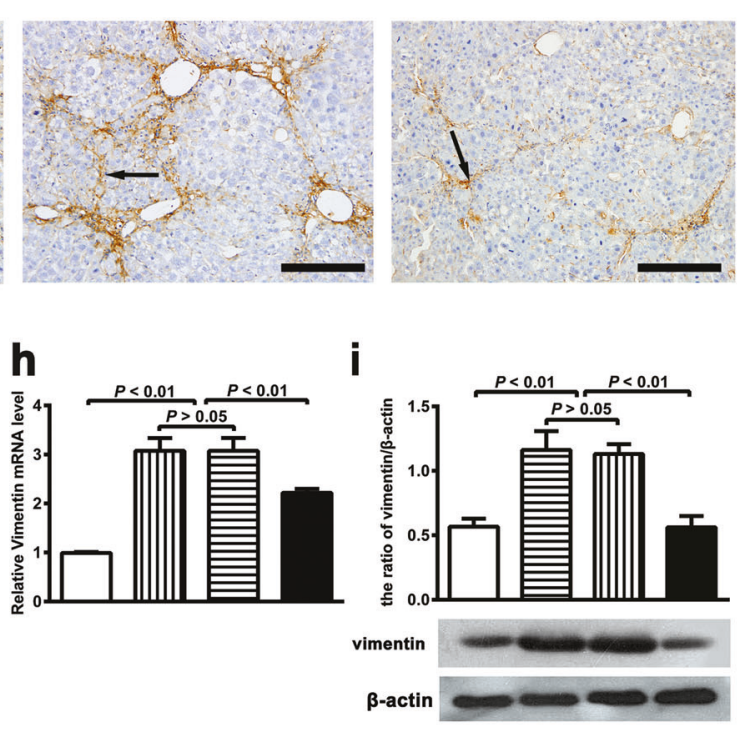

Fig. 4 Ectopic expression of HIP/PAP inhibits activation of hepatic stellate cells in fibrotic livers. qRT-PCR and western blot analyses showed that administration of AdHIP/PAP significantly alleviated $\mathrm{CCl}_{4}$-induced overexpression of $\alpha$-SMA $(\mathbf{a}, \mathbf{b})$ and vimentin $(\mathbf{c}, \mathbf{d})$ in mouse livers. Immunohistochemistry confirmed the alterations in

hepatic $\alpha$-SMA expression (e). The protective effect of AdHIP/PAP on liver fibrosis was also validated in a murine BDL model $(\mathbf{f}-\mathbf{j})$. Error bars indicate SD. Arrows indicate positive $\alpha$-SMA immunostaining. Scale bars $=100 \mu \mathrm{m}$

EMT in hepatic fibrosis [29-32]. To test whether HIP/PAP affects the EMT of hepatocytes, we performed qRT-PCR, western blot and immunofluorescence to determine the expression of E-cadherin, an epithelium marker, and vimentin, a mesenchymal marker, in LO2 cells under TGF$\beta 1$ stimulation. The results consistently showed that HIP/ PAP distinctly attenuated TGF- $\beta 1$-induced downregulation of E-cadherin and upregulation of vimentin but did not affect their basal expression in LO2 cells (Fig. 6b-e), indicating that HIP/PAP can inhibit TGF- $\beta 1$-induced EMT of hepatocytes.

\section{HIP/PAP downregulates TGF- $\beta$ receptor II (TGF- $\beta$ RII) expression in hepatic stellate cells and hepatocytes}

To elucidate the underlying mechanisms of HIP/PAP blunting the TGF- $\beta 1$-mediated signaling pathway, the cell surface TGF- $\beta 1$ receptor TGF- $\beta$ RII was determined in 
Fig. 5 HIP/PAP inhibits hepatic stellate cell proliferation and attenuates TGF- $\beta 1$-induced hepatic stellate cell activation and collagen synthesis. A CCK8 assay revealed that $\mathrm{rHIP/PAP}$ suppressed LX-2 proliferation in a dose-dependent manner (a). qRT-PCR and western blot analyses showed that rHIP/PAP $(125 \mathrm{ng} / \mathrm{ml})$ significantly abated TGF- $\beta 1$ ( $5 \mathrm{ng} / \mathrm{ml})$-induced upregulation of $\alpha$-SMA $(\mathbf{b}, \mathbf{c})$ and vimentin $(\mathbf{d}, \mathbf{e})$, while its effects on the basal expression of $\alpha$-SMA and vimentin were negligible in LX-2 cells. TGF$\beta 1$-induced upregulation of Col1A2 and Col3A1 expression was abolished by rHIP/PAP in LX-2 cells (f, g). Moreover, TGF- $\beta 1$-induced phosphorylation of Smad2/3 (p-Smad2/3) was obviously suppressed by rHIP/PAP in LX2 cells (h). The above effects of rHIP/PAP on hepatic stellate cells were further validated in HSC-T6 cells (i-m). The results are presented as the mean $\pm \mathrm{SD}$ from three independent experiments. $* P<0.05$ and $* * P<0.01$ vs the $0 \mathrm{ng} / \mathrm{ml} \mathrm{HIP/}$ PAP group at the same time point

\section{LX-2}

a

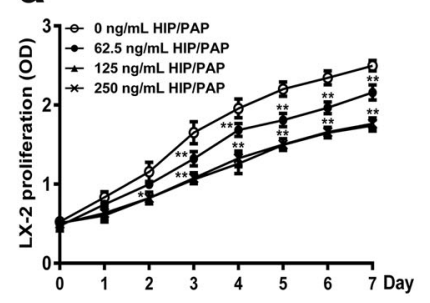

b

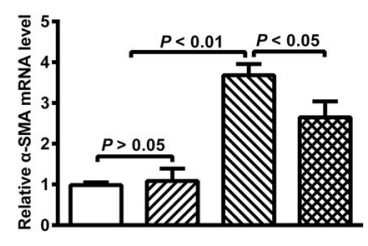

e
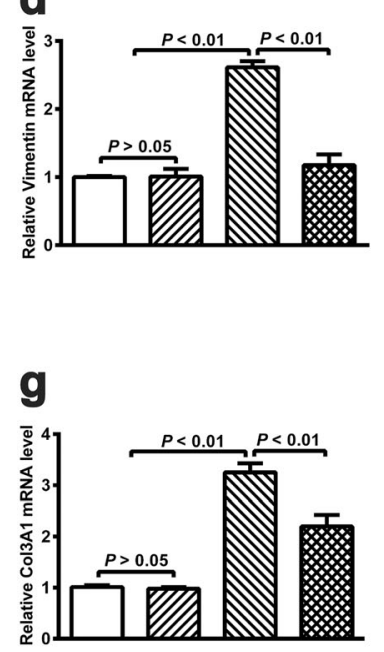

h
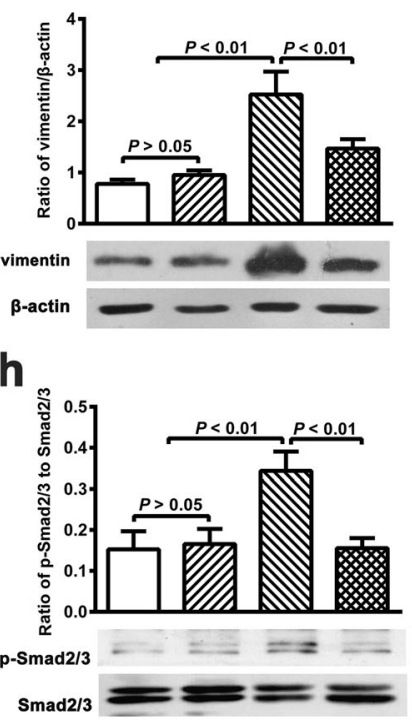

HSC-T6
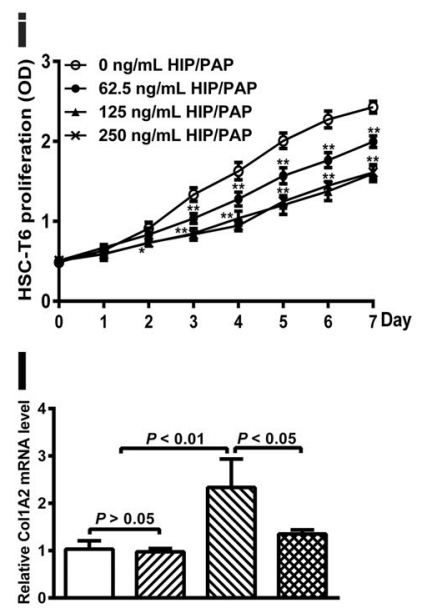

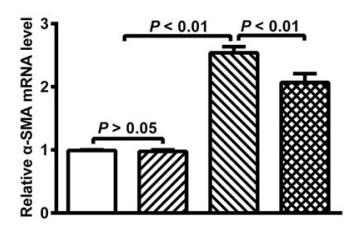

m

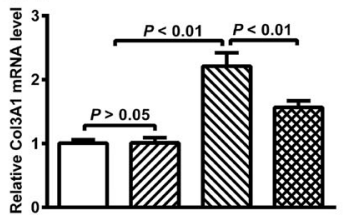

C

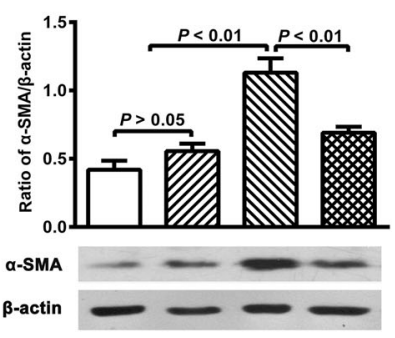

f

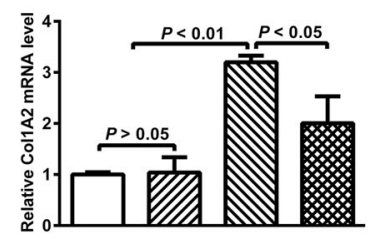

$\square$ Control

ש rHIP/PAP

ه TGF- $\beta 1$

TGF- $\beta 1+$ rHIP/PAP j

PAP markedly decreased the expression of hepatic TGF$\beta$ RII compared with that in either NC or AdGFP mice (Fig. 7c). In vitro experiments showed that, as previously reported $[33,34]$, the expression of TGF- $\beta$ RII at both the mRNA and protein levels was sharply decreased by TGF- $\beta 1$ $(5 \mathrm{ng} / \mathrm{ml})$ in cultured hepatocytes and HSCs, indicating a mouse livers as well as in in vitro cultured hepatocytes and HSCs. TGF- $\beta$ RII expression was upregulated in $\mathrm{CCl}_{4}$-treated (Fig. 7a) and BDL-induced (Fig. 7b) fibrotic mouse livers at both the mRNA and protein levels, while this increase was significantly attenuated by AdHIP/PAP. Moreover, in nonfibrotic mice, administration of AdHIP/ 
a
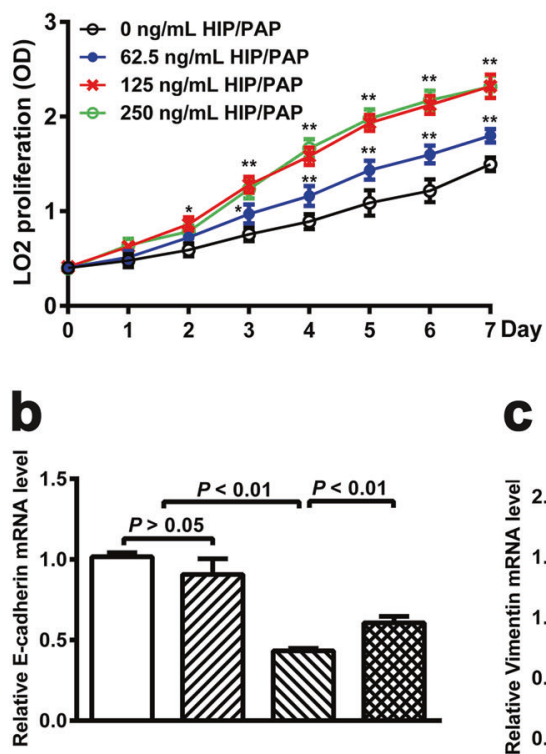

C d
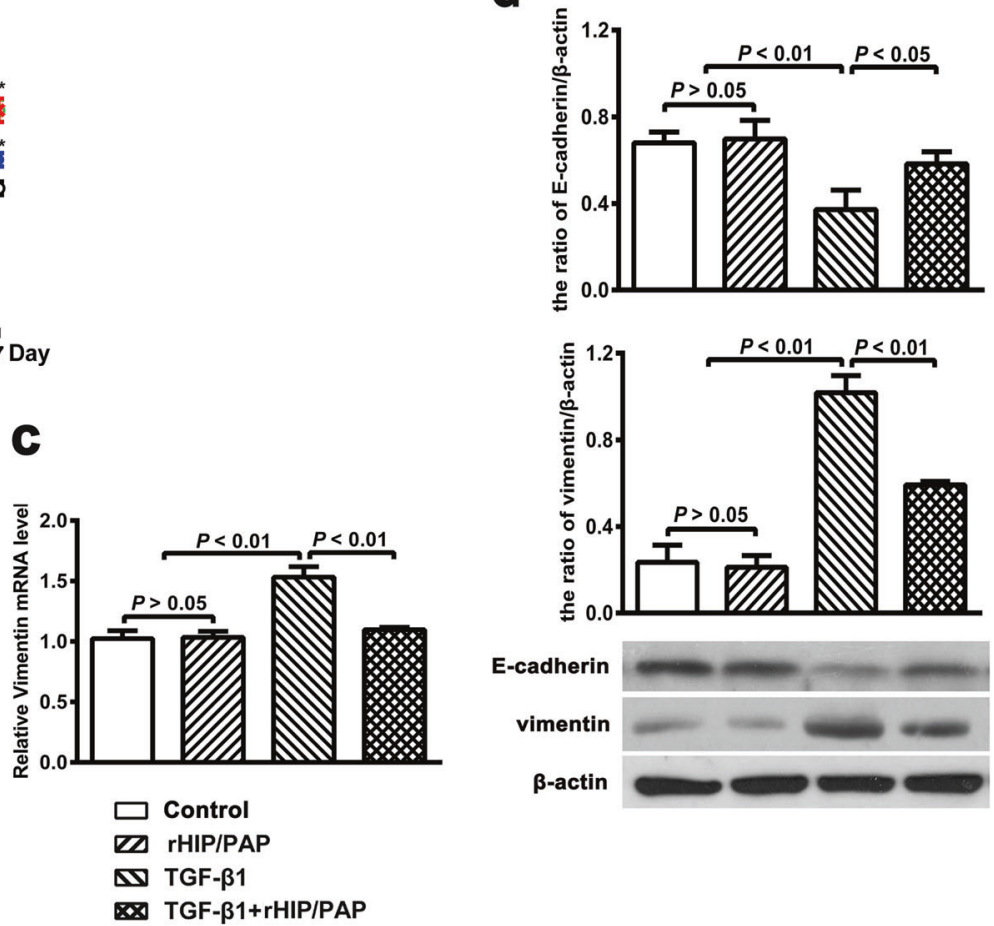

TGF- $\beta 1+$ rHIP/PAP
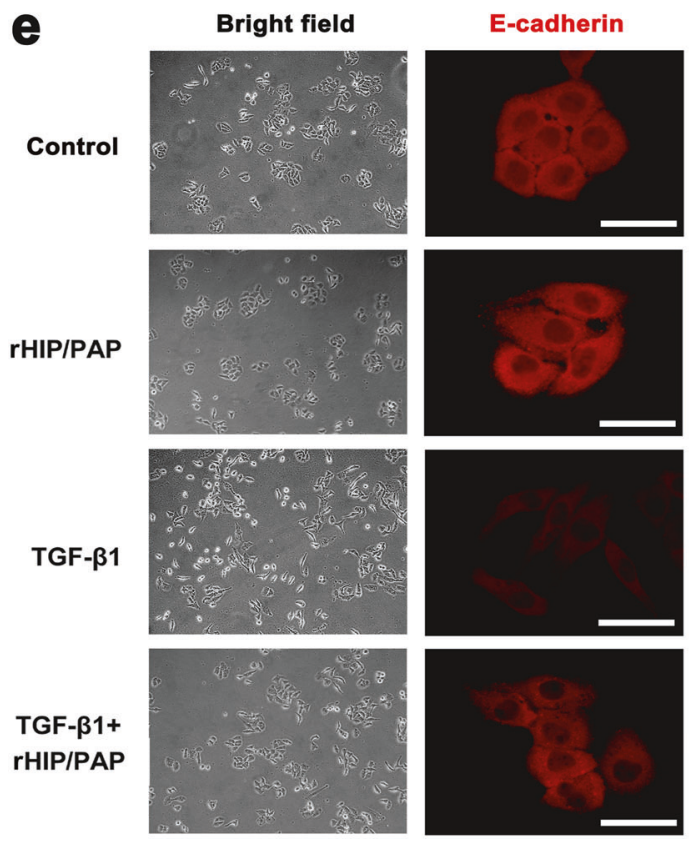
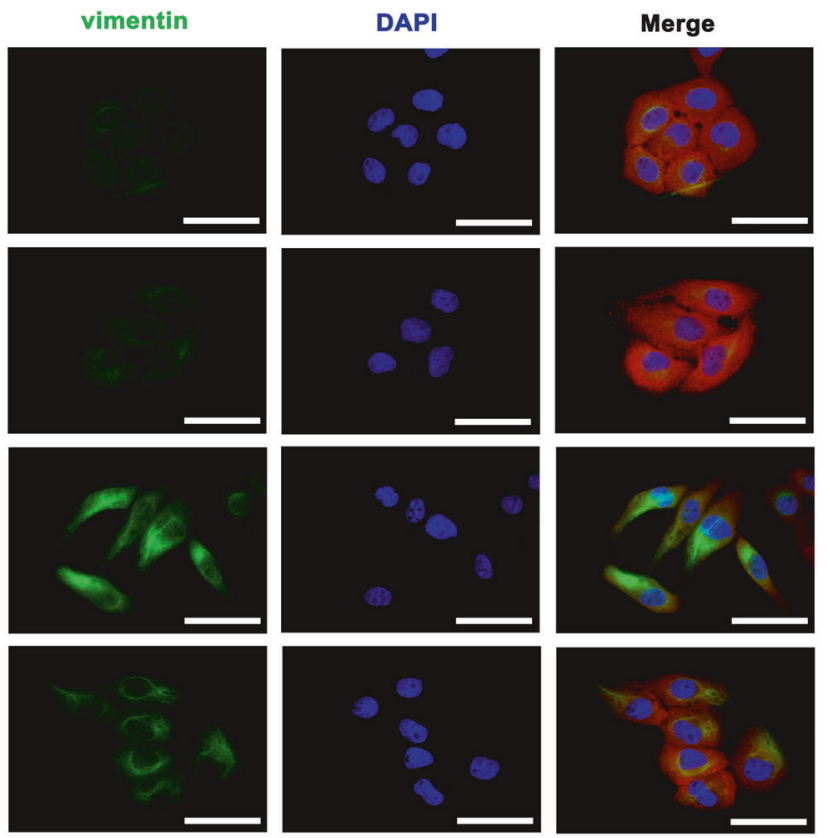

Fig. 6 HIP/PAP accelerates proliferation while inhibiting TGF- $\beta 1$ induced EMT in cultured hepatocytes. rHIP/PAP accelerated the proliferation of $\mathrm{LO} 2$ cells in a dose-dependent manner. $* P<0.05$ and ${ }^{* *} P<0.01$ vs the $0 \mathrm{ng} / \mathrm{ml}$ HIP/PAP group at the same time point (a). qRT-PCR (b, c), western blots (d), and immunofluorescence (e) showed

that TGF- $\beta 1(5 \mathrm{ng} / \mathrm{ml})$ inhibited the expression of E-cadherin, a marker of epithelial cells, and increased the expression of vimentin, a marker of mesenchymal cells, in cultured LO2 cells, while these alterations were attenuated by rHIP/PAP. The results are presented as the mean \pm SD from three independent experiments. Scale bars $=50 \mu \mathrm{m}$

\section{Discussion}

feedback mechanism of TGF- $\beta 1$ stimulation. Similarly, downregulation of TGF- $\beta$ RII was also induced by rHIP/ PAP $(125 \mathrm{ng} / \mathrm{ml})$ in LO2, LX-2, and HSC-T6 cells, while the combination of rHIP/PAP and TGF- $\beta 1$ did not show a further decrease in TGF- $\beta$ RII expression (Fig. 7d-f).

In this study, we first provided substantial evidence for the increased expression of HIP/PAP and its mouse counterpart, Reg3B, in fibrotic human and mouse livers, with 
a
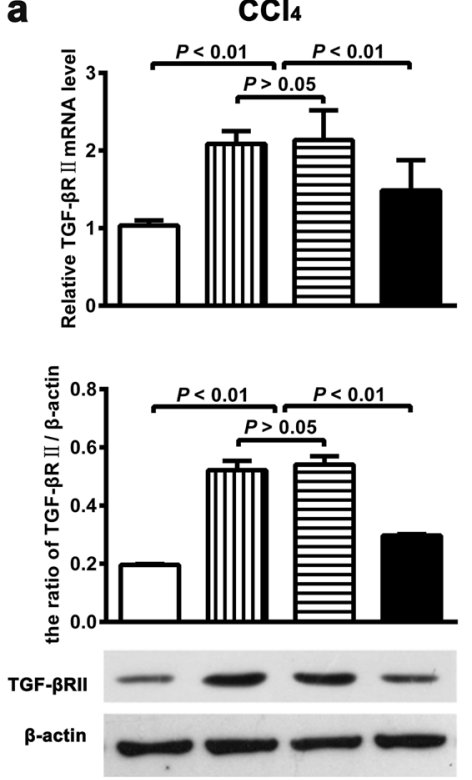

$\square \mathrm{NC}$

m. $\mathrm{CCl}_{4}$

曰 $\mathrm{AdGFP}+\mathrm{CCl}_{4}$

- Ad.HIP/PAP $+\mathrm{CCl}_{4}$

d

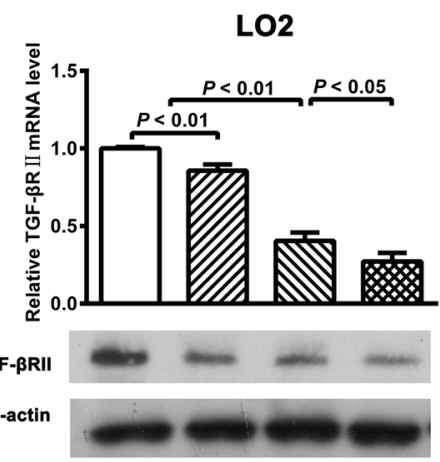

b
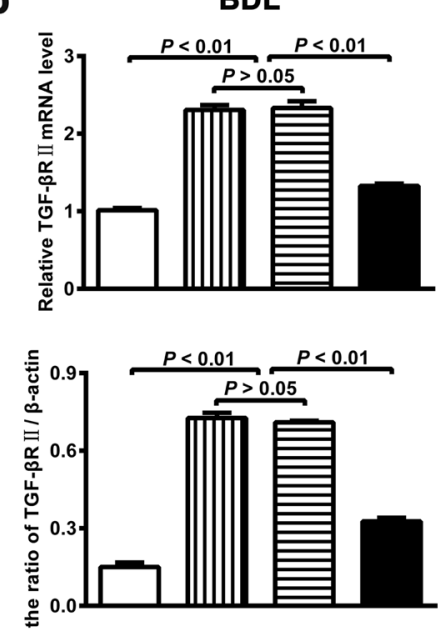

TGF-BRII

$\beta$-actin

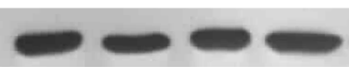

\section{$\square$ Sham}

四 BDL

$\triangle$ AdGFP+BDL

- AdHIPIPAP+BDL

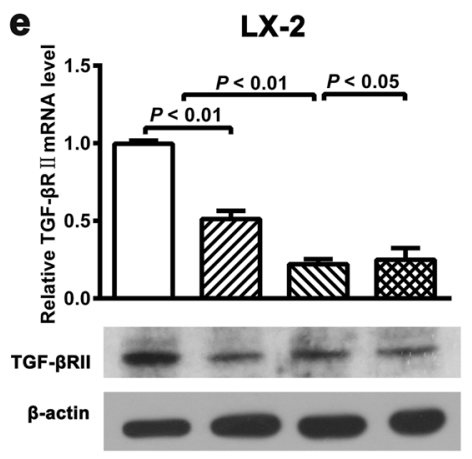

$\square$ Control

ED rHIP/PAP

DV TGF- $\beta 1$

TGF- $\beta 1+$ rHIP/PAP
C
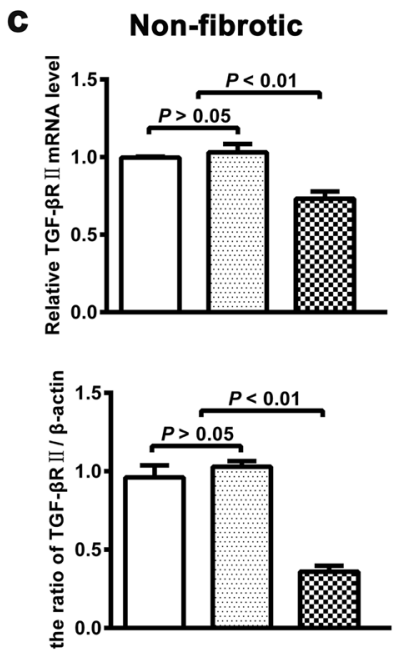

TGF- $\beta$ RII

$\beta$-actin

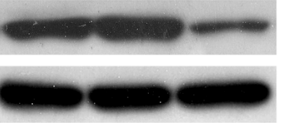

$\square$ NC

AdGFP

m AdHIP/PAP

f

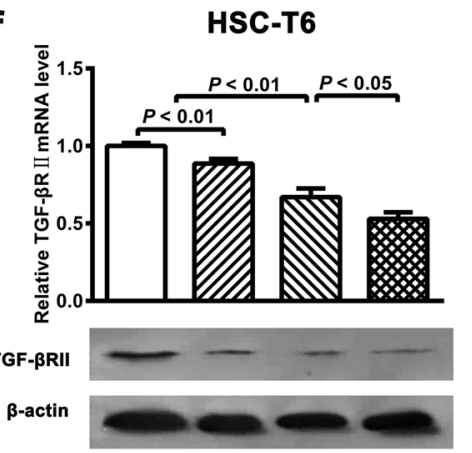

Fig. 7 HIP/PAP downregulates the expression of TGF- $\beta$ RII in fibrotic and nonfibrotic mouse livers as well as in cultured hepatocytes and hepatic stellate cells. Both qRT-PCR and western blot analyses showed that TGF- $\beta$ RII expression was upregulated in $\mathrm{CCl}_{4}-$ and BDL-induced fibrotic mouse livers, while this increase was significantly attenuated by AdHIP/PAP (a, b). Administration of AdHIP/
PAP significantly reduced the basal expression of TGF- $\beta$ RII in nonfibrotic mouse livers (c). The expression of TGF- $\beta$ RII, at both the mRNA and protein levels, was sharply downregulated by rHIP/PAP $(125 \mathrm{ng} / \mathrm{ml})$ in in vitro cultured LO2 (d), LX-2 (e), and HSC-T6 (f) cells. Error bars indicate the SD

related cytokines IL-10, IL-6, and TNF- $\alpha$ strongly induced Reg3B expression in mouse liver, while the profibrotic cytokine TGF- $\beta 1$ only showed a marginal effect.

The $\mathrm{CCl}_{4}$ model displays all important properties of human liver fibrosis, including inflammation, regeneration, and fiber formation. BDL is the most common model used to induce obstructive cholestatic injury in mice [36]. In this study, we observed the effects of adenovirus-mediated HIP/ PAP ectopic expression on both $\mathrm{CCl}_{4^{-}}$and BDL-induced liver injury and subsequent hepatic fibrosis. In agreement 
with previous reports $[12,16,17]$, our study showed that ectopic HIP/PAP significantly alleviated $\mathrm{CCl}_{4}-$ and BDLinduced liver injury, inflammation and the overproduction of proinflammatory cytokines, such as IL- $1 \beta$, IL- 6 , TNF- $\alpha$, and IL-17A, while further increasing the expression of the anti-inflammatory cytokine IL-10. In vivo experiments with nonfibrotic mice and in vitro tests verified that HIP/PAP exerts direct modulating effects on the expression of inflammatory cytokines in hepatocytes, apart from monocytes/Kupffer cells, as reported elsewhere [37]. Liver injury and subsequent inflammation are the precursor lesions of hepatic fibrosis; hence, it is reasonable that alleviating liver injury and inflammation prevents liver fibrosis. In addition, proinflammatory cytokines, such as IL-1 $\beta$ [38], IL-6 [39], TNF- $\alpha$ [40], and IL-17A [41] aggravate, while the antiinflammatory cytokine IL-10 [21] confers protection on hepatic fibrosis. The modulation of these proinflammatory cytokines in injured livers might also contribute to the antifibrotic effect of HIP/PAP. In addition, our study demonstrated that HIP/PAP can suppress hepatic fibrogenesis through other mechanisms.

Propagation and activation of HSCs is a pivotal event during the onset and maintenance of hepatic fibrosis [2]. Quiescent HSCs, as the major storage sites of vitamin A, express markers that are characteristic of adipocytes (PPAR $\gamma$, SREBP-1c, and leptin). During activation, HSCs express myogenic markers ( $\alpha$-SMA, vimentin, and c-myb) and thus gain a myofibroblast-like phenotype [3, 42]. In addition, many studies have shown that the EMT of hepatocytes contributes to myofibroblasts, at least in animal models [29-32]. Our in vivo results showed that HIP/PAP reduced myofibroblasts in $\mathrm{CCl}_{4}$-intoxicated and BDL mouse livers. In vitro experiments showed that HIP/ PAP suppressed HSC proliferation in a dose-dependent manner. Moreover, HIP/PAP attenuated TGF- $\beta 1$-induced activation of HSCs and inhibited phosphorylation of Smad2/3 in HSCs. These results indicate that HIP/PAP attenuates hepatic fibrosis by suppressing the proliferation and activation of HSCs. In addition, HIP/PAP significantly attenuated TGF- $\beta 1$-induced downregulation of E-cadherin, an epithelial marker, and upregulation of vimentin, a mesenchymal marker, in cultured hepatocytes, strongly suggesting that inhibition of TGF- $\beta 1$-induced hepatocyte EMT might contribute to the antifibrotic effects of HIP/PAP.

TGF- $\beta 1$ has been recognized as the key mediator in hepatic fibrosis due to its role as an amplifier by upregulating its own expression and other profibrotic factors, such as PDGFs, CTGF, and PAI-1 [43-45], as well as its strong promotion of HSC proliferation and activation $[46,47]$. PDGFs, especially PDGF-B, are potent mitogens for HSCs [48-50]. CTGF acts as a downstream effector and booster of TGF- $\beta 1$ to facilitate fibrogenesis
$[32,44,51]$. PAI-1, the most abundant protein among the known activators and inhibitors of the fibrinolysis system, has been shown to participate in fibrosis through multiple pathways [45, 52, 53]. Our experiments showed that HIP/ PAP suppressed TGF- $\beta 1$-induced but not basal expression of TGF- $\beta 1$, PDGF-A, PDGF-B, CTGF, and PAI- 1 in hepatocytes and HSCs. These results, along with the effects of HIP/PAP on TGF- $\beta 1$-induced HSC activation and hepatocyte EMT, collectively indicate that blunting TGF- $\beta 1$ signaling is critically involved in the antifibrotic effect of HIP/PAP.

The TGF- $\beta$ receptor complex is composed of type I and type II serine/threonine kinase receptors. TGF- $\beta$ s initially bind to TGF- $\beta$ RII, which in turn forms the functional receptor with TGF- $\beta$ RI and phosphorylates it. Signals are propagated to the SMAD family of proteins, which activate downstream signaling molecules. Studies in both humans and animal models have shown that TGF- $\beta$ RII expression is augmented in cirrhotic/fibrotic livers [54-56]. Our in vivo experiments demonstrated that ectopic expression of HIP/PAP significantly suppressed not only the elevated expression of TGF- $\beta$ RII in fibrotic mouse livers but also the basal expression of TGF- $\beta$ RII in nonfibrotic mouse livers. Consistently, in vitro tests showed that HIP/PAP significantly downregulated the expression of TGF- $\beta$ RII in HSCs and hepatocytes. Downregulation of TGF- $\beta$ RII in HSCs leads to insensitivity to TGF- $\beta 1$ stimulation and subsequently the profibrogenic effects of TGF- $\beta 1$. TGF$\beta R I I$ downregulation in hepatocytes abrogates the antiproliferative [57], proapoptotic [58], and EMT-promoting effects of TGF- $\beta 1$ in hepatocytes. These results indicate that downregulating TGF- $\beta$ RII expression is one of the important underlying mechanisms for HIP/PAP in suppressing hepatic fibrosis.

In conclusion, our study demonstrated that elevated expression of HIP/PAP during liver injury and inflammation serves as a counteracting mechanism to protect against subsequent fibrogenesis. Supplementation of exogenous HIP/PAP or enhancing its endogenous expression should be therapeutically beneficial not only to manage acute liver injury but also to relieve liver fibrosis.

Acknowledgements This study was supported by the National Natural Science Foundation of China (Nos. 81070351, 81170383). We thank Honghong $\mathrm{Li}$ at the Department of Pathology, the First Affiliated Hospital of Xi' an Jiaotong University, for his technical assistance.

\section{Compliance with ethical standards}

Conflict of interest The authors declare that they have no conflict of interest.

Publisher's note Springer Nature remains neutral with regard to jurisdictional claims in published maps and institutional affiliations. 


\section{References}

1. Koyama Y, Brenner DA. Liver inflammation and fibrosis. J Clin Investig. 2017;3:55-64.

2. Friedman SL. Evolving challenges in hepatic fibrosis. Nat Rev Gastroenterol Hepatol. 2010;7:425-36.

3. Bataller R, Brenner DA. Liver fibrosis. J Clin Investig. 2005;115: 209-18.

4. Jiang JX, Chen X, Hsu DK, Baghy K, Serizawa N, Scott F, et al. Galectin-3 modulates phagocytosis-induced stellate cell activation and liver fibrosis in vivo. Am J Physiol Gastrointest Liver Physiol. 2012;302:G439-46.

5. Wu MH, Chen YL, Lee KH, Chang CC, Cheng TM, Wu SY, et al. Glycosylation-dependent galectin-1/neuropilin-1 interactions promote liver fibrosis through activation of TGF- $\beta$ - and PDGF-like signals in hepatic stellate cells. Sci Rep. 2017;7:11006.

6. Seifert L, Deutsch M, Alothman S, Alqunaibit D, Werba G, Pansari M, et al. Dectin-1 regulates hepatic fibrosis and hepatocarcinogenesis by suppressing TLR4 signaling pathways. Cell Rep. 2015;13:1909-21.

7. Nata K, Liu Y, Xu L, et al. Molecular cloning, expression and chromosomal localization of a novel human REG family gene, REG III. Gene. 2004;340:161-70.

8. Liu JL, Cui W. Which gene, Reg2 or Reg3, was targeted that affected liver regeneration? Hepatology. 2007;45:1584-5.

9. Christa L, Carnot F, Simon MT, Levavasseur F, Stinnakre MG, Lasserre $\mathrm{C}$, et al. HIP/PAP is an adhesive protein expressed in hepatocarcinoma, normal paneth, and pancreatic cells. Am J Physiol. 1996;271:993-1002.

10. Christa L, Simon MT, Brezault-Bonnet C, Bonte E, Carnot F, Zylberberg $\mathrm{H}$, et al. Hepatocarcinoma-intestine-pancreas/pancreatic associated protein (HIP/PAP) is expressed and secreted by proliferating ductules as well as by hepatocarcinoma and cholangiocarcinoma cells. Am J Pathol. 1999;155:1525-33.

11. Mukherjee S, Zheng H, Derebe MG, Callenberg KM, Partch CL, Rollins D, et al. Antibacterial membrane attack by a pore-forming intestinal C-type lectin. Nature. 2014;505:103-7.

12. Moniaux N, Song H, Darnaud M, Garbin K, Gigou M, Mitchell C, et al. Human hepatocarcinoma-intestine-pancreas/pancreatitisassociated protein cures fas-induced acute liver failure in mice by attenuating free-radical damage in injured livers. Hepatology. 2011;53:618-27.

13. Heller A, Fiedler F, Schmeck J, Lück V, Iovanna JL, Koch T. Pancreatitis-associated protein protects the lung from leukocyteinduced injury. Anesthesiology. 1999;91:1408-14.

14. Gironella M, Folch-Puy E, LeGoffic A, Garcia S, Christa L, Smith A, et al. Experimental acute pancreatitis in PAP/HIP knock-out mice. Gut. 2007;56:1091-7.

15. Lv YF, Yang XF, Huo YW, Tian H, Li S, Yin Y, et al. Adenovirusmediated hepatocarcinoma-intestine-pancreas/pancreatitis-associated protein suppresses dextran sulfate sodium-induced acute ulcerative colitis in rats. Inflamm Bowel Dis. 2012;18:1950-60.

16. Simon MT, Pauloin A, Normand G, Lieu HT, Mouly H, Pivert G, et al. HIP/PAP stimulates liver regeneration after partial hepatectomy and combines mitogenic and antiapoptotic functions through the PKA signaling pathway. FASEB J. 2003;17:1441-50.

17. Lieu HT, Simon MT, Nguyen-Khoa T, Kebede M, Cortes A, Tebar L, et al. Reg2 inactivation increases sensitivity to Fas hepatotoxicity and delays liver regeneration post-hepatectomy in mice. Hepatology. 2006;44:1452-64.

18. Ortiz EM, Dusetti NJ, Vasseur S, Malka D, Bödeker H, Dagorn $\mathrm{JC}$, et al. The pancreatitis-associated protein is induced by free radicals in AR42J cells and confers cell resistance to apoptosis. Gastroenterology. 1998;114:808-16.

19. Nalpas B, Ichaï P, Jamot L, Carbonell N, Rudler M, Mathurin P, et al. A proof of concept, phase II randomized european trial, on the efficacy of ALF-5755, a novel extracellular matrix-targeted antioxidant in patients with acute liver diseases. PLoS ONE. 2016;11:e0150733.

20. Aggarwal S, Xie MH, Maruoka M, Foster J, Gurney AL. Acinar cells of the pancreas are a target of interleukin-22. J Interferon Cytokine Res. 2001;21:1047-53.

21. Folch-Puy E, Granell S, Dagorn JC, Iovanna JL, Closa D. Pancreatitis-associated protein I suppresses NF-kappa B activation through a JAK/STAT-mediated mechanism in epithelial cells. J Immunol. 2006;176:3774-9.

22. Malka D, Vasseur S, Bödeker H, Ortiz EM, Dusetti NJ, Verrando P, et al. Tumor necrosis factor alpha triggers antiapoptotic mechanisms in rat pancreatic cells through pancreatitis-associated protein I activation. Gastroenterology. 2000;119:816-28.

23. Smith TA, White BD, Gardner JM, Kaleko M, McClelland A. Transient immunosuppression permits successful repetitive intravenous administration of an adenovirus vector. Gene Ther. 1996; 3:496-502.

24. Walter J, You Q, Hagstrom JN, Sands M, High KA. Successful expression of human factor IX following repeat administration of adenoviral vector in mice. Proc Natl Acad Sci USA. 1996;93: 3056-61.

25. Yei S, Mittereder N, Tang K, O'Sullivan C, Trapnell BC. Adenovirus-mediated gene transfer for cystic fibrosis: quantitative evaluation of repeated in vivo vector administration to the lung. Gene Ther. 1994;1:192-200.

26. Zabner J, Ramsey BW, Meeker DP, Aitken ML, Balfour RP, et al. Repeat administration of an adenovirus vector encoding cystic fibrosis transmembrane conductance regulator to the nasal epithelium of patients with cystic fibrosis. J Clin Investig. 1996;97:1504-11.

27. Chen P, Kovesdi I, Bruder JT. Effective repeat administration with adenovirus vectors to the muscle. Gene Therapy. 2000;7:587-95.

28. Lurie Y, Webb M, Cytter-Kuint R, Shteingart S, Lederkremer GZ. Non-invasive diagnosis of liver fibrosis and cirrhosis. World $\mathrm{J}$ Gastroenterol. 2015;21:11567-83.

29. Zeisberg M, Yang C, Martino M, Duncan MB, Rieder F, Tanjore H, et al. Fibroblasts derive from hepatocytes in liver fibrosis via epithelial to mesenchymal transition. J Biol Chem. 2007;282:23337-47.

30. Nitta T, Kim JS, Mohuczy D, Behrns KE. Murine cirrhosis induces hepatocyte epithelial mesenchymal transition and alterations in survival signaling pathways. Hepatology. 2008;48:909-19.

31. Hao ZM, Cai M, Lv YF, Huang YH, Li HH. Oral administration of recombinant adeno-associated virus-mediated bonemorphogenetic protein-7 suppresses $\mathrm{CCl}_{4}$-induced hepatic fibrosis in mice. Mol Ther. 2012;20:2043-51.

32. Li S, Lv YF, Su HQ, Zhang QN, Wang LR, Hao ZM. A virus-like particle-based connective tissue growth factor vaccine suppresses carbon tetrachloride-induced hepatic fibrosis in mice. Sci Rep. 2016;6:32155.

33. Serrero G, Mills D. Decrease in transforming growth factor beta 1 binding during differentiation of rat adipocyte precursors in primary culture. Cell Growth Differ. 1991;2:173-8.

34. Roulot D, Sevcsik AM, Coste T, Strosberg AD, Marullo S. Role of transforming growth factor beta type II receptor in hepatic fibrosis: studies of human chronic hepatitis $\mathrm{C}$ and experimental fibrosis in rats. Hepatology. 1999;29:1730-8.

35. Wang Y, Jacovetti C, Li B, Siddique T, Xiong X, Yin H, et al. Coordinated age-dependent and pancreatic-specific expression of mouse Reg2Reg3 $\alpha$, and Reg3 $\beta$ genes. Growth Factors. 2011; 29:72-81.

36. Liedtke C, Luedde T, Sauerbruch T, Scholten D, Streetz K, Tacke $\mathrm{F}$, et al. Experimental liver fibrosis research: update on animal models, legal issues and translational aspects. Fibrogenesis Tissue Repair. 2013;6:19.

37. Vasseur S, Folch-Puy E, Hlouschek V, Garcia S, Fiedler F, Lerch $\mathrm{MM}$, et al. p8 improves pancreatic response to acute pancreatitis by 
enhancing the expression of the anti-inflammatory protein pancreatitis-associated protein I. J Biol Chem. 2004;20279:7199-207.

38. Zhang Y, Yao X. Role of c-Jun N-terminal kinase and p38/activation protein-1 in interleukin-1 $\beta$-mediated type I collagen synthesis in rat hepatic stellate cells. J Pathol Microbial Immunol. 2012;120:101-7.

39. Natsume M, Tsuji H, Harada A, Akiyama M, Yano T, Ishikura H, et al. Attenuated liver fibrosis and depressed serum albumin levels in carbon tetrachloride-treated IL-6-deficient mice. J Leukoc Biol. 1999;66:601-8.

40. Tomita K, Tamiya G, Ando S, Ohsumi K, Chiyo T, Mizutani A, et al. Tumour necrosis factor alpha signalling through activation of Kupffer cells plays an essential role in liver fibrosis of nonalcoholic steatohepatitis in mice. Gut. 2006;55:415-24.

41. Hara M, Kono H, Furuya S, Hirayama K, Tsuchiya M, Fujii H. Interleukin-17A plays a pivotal role in cholestatic liver fibrosis in mice. J Surg Res. 2013;183:574-82.

42. Rockey DC, Boyles JK, Gabbiani G, Friedman SL. Rat hepatic lipocytes express smooth muscle actin upon activation in vivo and in culture. J Submicrosc Cytol Pathol. 1992;24:193-203.

43. Pinzani M. PDGF and signal transduction in hepatic stellate cells. Front Biosci. 2002;7:d1720-26.

44. Gressner OA, Lahme B, Demirci I, Gressner AM, Weiskirchen R. Differential effects of TGF-beta on connective tissue growth factor (CTGF/CCN2) expression in hepatic stellate cells and hepatocytes. J Hepatol. 2007;47:699-710.

45. Zhang LP, Takahara T, Yata Y, Furui K, Jin B, Kawada N, et al. Increased expression of plasminogen activator and plasminogen activator inhibitor during liver fibrogenesis of rats: role of stellate cells. J Hepatol. 1999;31:703-11.

46. Kanzler S, Lohse AW, Keil A, Henninger J, Dienes HP, Schirmacher $\mathrm{P}$, et al. TGF- $\beta 1$ in liver fibrosis: an inducible transgenic mouse model to study liver fibrogenesis. Am J Physiol. 1999;276: G1059-68.

47. Fan X, Zhang Q, Li S, Lv Y, Su H, Jiang H, et al. Attenuation of $\mathrm{CCl}_{4}$-induced hepatic fibrosis in mice by vaccinating against TGFß1. PLoS ONE. 2013;8:e82190.

48. Borkham-Kamphorst E, Herrmann J, Stoll D, Treptau J, Gressner AM, Weiskirchen R. Dominant-negative soluble PDGF-beta receptor inhibits hepatic stellate cell activation and attenuates liver fibrosis. Lab Investig. 2004;84:766-77.
49. Czochra P, Klopcic B, Meyer E, Herkel J, Garcia-Lazaro JF, Thieringer $\mathrm{F}$, et al. Liver fibrosis induced by hepatic overexpression of PDGF-B in transgenic mice. J Hepatol. 2006; 45:19-428.

50. Hao ZM, Fan XB, Li S, Lv YF, Su HQ, Jiang HP, et al. Vaccination with platelet-derived growth factor $\mathrm{B}$ kinoids inhibits $\mathrm{CCl}_{4^{-}}$ induced hepatic fibrosis in mice. J Pharmacol Exp Ther. 2012;342:835-42.

51. Tong Z, Chen R, Alt DS, Kemper S, Perbal B, Brigstock DR. Susceptibility to liver fibrosis in mice expressing a connective tissue growth factor transgene in hepatocytes. Hepatology. 2009; 50:939-47.

52. Hu PF, Chen H, Zhong W, Lin Y, Zhang X, Chen YX, et al. Adenovirus-mediated transfer of siRNA against PAI-1 mRNA ameliorates hepatic fibrosis in rats. J Hepatol. 2009;51: 102-13.

53. Rabieian R, Boshtam M, Zareei M, Kouhpayeh S, Masoudifar A, Mirzaei H. Plasminogen activator inhibitor type-1 as a regulator of fibrosis. J Cell Biochem. 2018;119:17-27.

54. Baer HU, Friess H, Abou-Shady M, Berberat P, Zimmermann A, Gold LI, et al. Transforming growth factor betas and their receptors in human liver cirrhosis. Eur J Gastroenterol Hepatol. 1998;10:1031-9.

55. Calabrese F, Valente M, Giacometti C, Pettenazzo E, Benvegnu L, Alberti A, et al. Parenchymal transforming growth factor beta-1: its type II receptor and Smad signaling pathway correlate with inflammation and fibrosis in chronic liver disease of viral etiology. J Gastroenterol Hepatol. 2003;18:1302-8.

56. Yan C, Wang L, Li B, Zhang BB, Zhang B, Wang YH, et al. The expression dynamics of transforming growth factor- $\beta /$ Smad signaling in the liver fibrosis experimentally caused by Clonorchis sinensis. Parasit Vectors. 2015;8:70.

57. Nakamura T, Sakata R, Ueno T, Sata M, Ueno H. Inhibition of transforming growth factor beta prevents progression of liver fibrosis and enhances hepatocyte regeneration in dimethylnitrosaminetreated rats. Hepatology. 2000;32:247-55.

58. Sánchez A, Alvarez AM, Benito M, Fabregat I. Apoptosis induced by transforming growth factor-beta in fetal hepatocyte primary cultures: involvement of reactive oxygen intermediates. J Biol Chem. 1996;271:7416-22. 